\title{
Self-management of health care behaviors for COPD: a systematic review and meta-analysis
}

\author{
This article was published in the following Dove Press journal: \\ International Journal of COPD \\ 17 February 2016 \\ Number of times this article has been viewed
}

\author{
Kate Jolly' \\ Saimma Majothi' \\ Alice J Sitch ${ }^{\prime}$ \\ Nicola R Heneghan ${ }^{2}$ \\ Richard D Riley ${ }^{3}$ \\ David J Moore' \\ Elizabeth J Bates' \\ Alice MTurner ${ }^{4}$ \\ Susan E Bayliss' \\ Malcolm J Price' \\ Sally J Singh ${ }^{5}$ \\ Peymane Adab' \\ David A Fitzmaurice' \\ Rachel E Jordan'
}

'Institute of Applied Health Research, ${ }^{2}$ School of Sport, Exercise and

Rehabilitation Sciences, University of Birmingham, Edgbaston, Birmingham,

${ }^{3}$ Research Institute of Primary Care and Health Sciences, Keele University, Keele, Staffordshire, ${ }^{4}$ Institute of Inflammation and Ageing, University of Birmingham, Birmingham, ${ }^{5} \mathrm{Centre}$ for Exercise and Rehabilitation Science, University Hospitals of Leicester NHS Trust, Glenfield Hospital, Leicester, UK

Correspondence: Rachel E Jordan Institute of Applied Health Research, University of Birmingham, Edgbaston, Birmingham BI5 2TT, UK

Tel +44 I2I 4I47665

Email r.e.jordan@bham.ac.uk
Purpose: This systematic review aimed to identify the most effective components of interventions to facilitate self-management of health care behaviors for patients with COPD. PROSPERO registration number CRD42011001588.

Methods: We used standard review methods with a systematic search to May 2012 for randomized controlled trials of self-management interventions reporting hospital admissions or healthrelated quality of life (HRQoL). Mean differences (MD), hazard ratios, and 95\% confidence intervals (CIs) were calculated and pooled using random-effects meta-analyses. Effects among different subgroups of interventions were explored including single/multiple components and multicomponent interventions with/without exercise.

Results: One hundred and seventy-three randomized controlled trials were identified. Selfmanagement interventions had a minimal effect on hospital admission rates. Multicomponent interventions improved HRQoL (studies with follow-up $>6$ months St George's Respiratory Questionnaire (MD 2.40, 95\% CI 0.75-4.04, 2 57.9). Exercise was an effective individual component (St George's Respiratory Questionnaire at 3 months MD 4.87, 95\% CI 3.96-5.79, $I^{2} 0 \%$ ). Conclusion: While many self-management interventions increased HRQoL, little effect was seen on hospital admissions. More trials should report admissions and follow-up participants beyond the end of the intervention.

Keywords: COPD, self-management, systematic review, meta-analysis

\section{Background}

"Self-management" has been defined as "the ability of a patient to deal with all that a chronic disease entails, including symptoms, treatment, physical and social consequences and lifestyle changes". ${ }^{1}$ Within COPD, self-management interventions are very varied in delivery and content. Interventions are often multicomponent, commonly include exercise or physical activity support, disease education, recognition and management of exacerbations, respiratory muscle training, management of breathlessness, medication adherence, inhaler technique, smoking cessation, and relaxation. ${ }^{2}$ Different behavioral change techniques underpin interventions.

An important driver for self-management is potential savings in health care costs from reducing hospital admissions. Patients with COPD have high rates of emergency department visits and hospital admissions and are costly to health services. ${ }^{3,4}$ The huge diversity of potential self-management interventions makes it difficult for commissioners and providers of health services to select the most effective model of self-management support for people with COPD. To address this, we undertook a wide systematic review of interventions which included supported self-management for COPD to explore the effectiveness of various configurations on all-cause hospital admissions and health-related quality of life (HRQoL). 


\section{Methods}

\section{Study design}

Systematic review of the effectiveness of COPD selfmanagement interventions on hospital admissions and HRQoL measured by the St George's Respiratory Questionnaire (SGRQ) and Chronic Respiratory Disease Questionnaire (CRQ) total scores and reported according to Preferred Reporting Items for Systematic Reviews and Meta-Analyses. This was part of a larger review registered in PROSPERO (CRD42011001588). The aim was to identify which individual or combination of components was most effective. No ethical approval was required for this review as it used secondary published data.

\section{Definition of self-management for this review}

Self-management interventions were defined as those which involve collaboration between health care professional and patient so the patient acquires and demonstrates knowledge and skills required to manage their medical regimens, change their health behavior, improve control of their disease, and improve their well-being. ${ }^{5}$ Guided by our patient participation group, a list of interventions/components was drawn up which were considered as self-management for this review (Table S1). Given the absence of a universally agreed definition of self-management, we took a very broad definition of self-management as it is known that there is a spectrum of interventions. ${ }^{6}$ We excluded trials where the intervention was largely done to the patient by a professional such as a physiotherapy intervention involving handling of a patient; hospital-at-home or disease-management interventions were only included if they described a self-management component.

\section{Literature search and inclusion criteria}

Potentially relevant citations were identified through comprehensive electronic searches from inception of the following bibliographic databases to May 2012: MEDLINE, MEDLINE In Process and EMBASE via Ovid, Cochrane (Wiley) Central Register of Controlled Trials (CENTRAL) and Science Citation Index (ISI), PEDro, PsycINFO (Ovid), and Cochrane Airways specialized register; (eg, search strategy in Supplementary materials). Reference lists of retrieved articles and relevant reviews were manually searched. Additional literature was identified through contacts with experts in the field.

To be included, trials had to have used randomization to create the study groups; required at least $90 \%$ of the population to have COPD; reported a self-management intervention; reported hospital admissions or HRQoL; and were not solely smoking cessation.

No language restrictions were applied. Inclusion and exclusion criteria were applied to all citations and full texts of potentially relevant papers by two reviewers independently. Co-reviewers were consulted where there was uncertainty.

\section{Data extraction and risk of bias assessment}

Data were extracted directly into tables; key characteristics (number of participants, duration of intervention, and follow-up) were all double checked and $20 \%$ of outcome data checked. To ensure consistency, one person (SM) categorized intervention components in all trials after the research team had each mapped 30 studies and discussed discrepancies and component definitions/criteria. Risk of bias was assessed according to methods in the Cochrane Handbook, assessing sequence generation, allocation concealment, blinding of personnel and participants (by outcome), incomplete outcome data (by outcome), selective outcome reporting and other potential threats to validity. ${ }^{7}$

\section{Data synthesis}

For effect estimates of admissions over follow-up, hazard ratios (HR) were used. Only first admissions were used as it was not possible to combine different types of measures without making assumptions. Where HR were not directly reported, methods of Parmar et $\mathrm{al}^{8}$ or Perneger were used. ${ }^{9}$ Where there were zero cells, a continuity correction ( $1 /$ sample size of the opposite group) was added to each cell. ${ }^{10}$

For HRQoL, reported mean difference (MD) estimates and $95 \%$ confidence intervals (CIs) calculated from an analysis of covariance were preferred. Otherwise, MD reported from an analysis of change scores, an analysis of final scores or change value were used (preferenced in that order). The SGRQ MD results were multiplied by -1 to ensure that all estimates related to the same direction of effect. Where data were missing they were not imputed, nor were authors contacted due to the large volume of papers.

In order to explore the effectiveness of different selfmanagement components (or groups of components), a series of analyses was planned prior to collation of the data and followed two main objectives: i) to explore clinically relevant subgroups; ii) to avoid repeating any recent high-quality systematic review. We explored effectiveness of any singlecomponent interventions delivered alone or where the only difference between the two arms was this single component. 
A multicomponent self-management package was defined as including three or more relevant components.

A random-effects meta-analysis model was used to synthesize effect estimates across trials ${ }^{11}$ to account for between-trial heterogeneity in intervention effects, and was estimated using methods of moments. ${ }^{11} \mathrm{MD}$ were pooled on the original scale, and HR pooled on the $\log _{\mathrm{e}}$ scale. Heterogeneity across studies was summarized using $I^{2}$ statistic. ${ }^{12}$ Trials reporting the SGRQ and CRQ were not combined because they report different domains (SGRQ: symptoms, activity, and impact; CRQ: dyspnea, fatigue, emotional functioning, and mastery).

Where two or more interventions from the same study contributed to the same meta-analysis, as they shared the same control group, the standard errors of their effect estimates were inflated, essentially by dividing the sample size in the control group by number of comparisons it contributed to within the meta-analysis. ${ }^{13}$ For meta-analyses containing ten or more studies, small study effects (potential publication bias) were investigated by examining asymmetry on a funnel plot and calculating Egger's test, with $P<0.1$ taken as statistically significant. Potential causes of heterogeneity, such as number of components, duration of intervention, and follow-up were explored visually through Forest plots and by subgroup analyses.

\section{Results}

From 13,355 identified titles, 836 full papers were obtained, 283 papers were included, and 173 randomized controlled trials from 193 papers reported one of the two primary outcomes: HRQoL and hospital admissions/readmissions (Figure 1). Within the 173 trials, several studies had multiple arms, thus there were 226 randomized comparisons of interventions compared to usual care, control or another active intervention.

\section{Populations and settings}

The 173 trials were set in 31 countries with most from high-income countries, 33 (19.1\%) from the USA and 21 (12.1\%) from the UK (Table 1). Sample sizes ranged from 10 to 743 , median 53 (interquartile range [IQR] 38, 100). Trials were generally small with 81 (46.8\%) including less than 50 participants. The participant characteristics reported were frequently only of those who completed the trial, rather than all those randomized.

The mean age of participants was between 52 and 80 years; males tended to be in the majority. Mean $\mathrm{FEV}_{1} \%$ predicted of trial participants ranged from $26.3 \%$ to $69 \%$. Approximately $20 \%$ of trials did not report the mean $\mathrm{FEV}_{1} \%$ predicted, reporting other measures of lung function. These were consistent with moderate to severe COPD. More than half of trials had a population mean in the 30\%-59\% range, equivalent to GOLD stage 3, severe COPD. Recruitment of participants was mainly from secondary care or pulmonary rehabilitation programs.

\section{Trial design}

Length of follow-up was frequently short, in 78 (45.1\%) 3 months or less, and $106(61.3 \%)$ of trials only reported follow-up data at the end of the intervention period (Table 1).

\section{The interventions}

The interventions were very heterogeneous. They included structured group-based pulmonary rehabilitation programs (which aim to teach self-management skills); more limited one-to-one educational self-management interventions delivered in an outpatient setting or at a patient's home, sometimes with telephone follow-up; integrated disease management with multidisciplinary input and often some element of monitoring by health professionals; exercise-only interventions (with some dyspnea management) and respiratory muscle training using threshold devices. Within these various broad categories, there were a range of individual self-management components.

We categorized 15 types of components. Exercise was the most commonly reported component $(77.9 \%)$ in interventions, followed by breathing techniques and management of dyspnea (64.6\%) and general education about COPD and its management (47.8\%) (Table S2). Up to 13 different self-management components were included in any one of the intervention arms with $73(32.3 \%)$ having six or more components. Thirty-seven (16.4\%) were single-component interventions with the vast majority of these being exercise-only (mixture of supervised and unsupervised exercise). The behavioral change elements were rarely reported in sufficient detail for categorization beyond information giving and other techniques.

The duration and mode of interventions are in Table 1; 113 trials $(65.3 \%)$ reported interventions of 3 months duration or less; most were delivered by nurses and respiratory physiotherapists and half had a group-based component.

\section{Comparator arms}

There were 139 comparisons (from 126 trials) of an intervention compared with usual care or control group that was not an active intervention. The usual care arm was frequently not described; in other cases, it was standard primary and/or secondary care for people with COPD. 


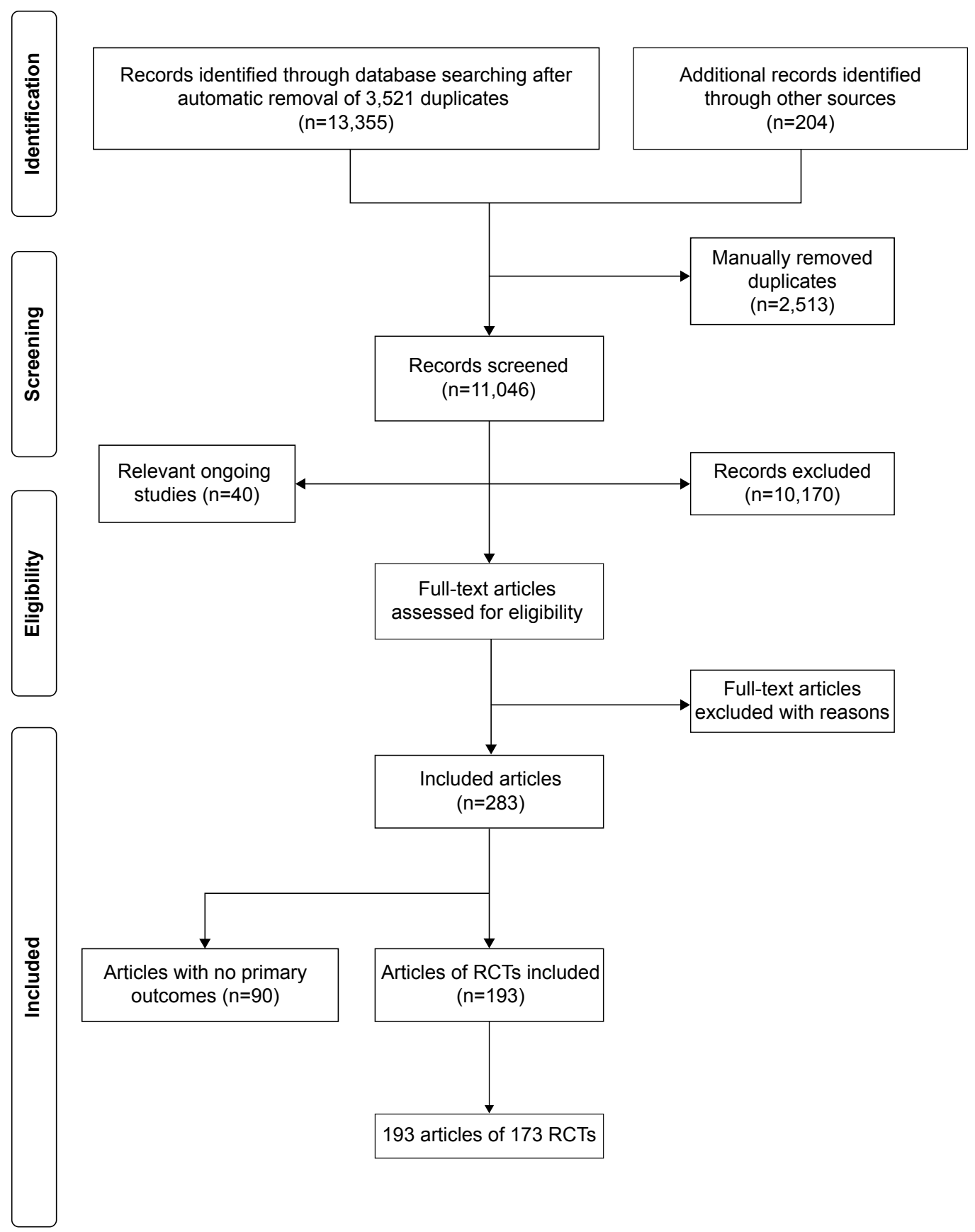

Figure I Flow diagram summarizing the study selection process.

Abbreviaiton: RCT, randomized controlled trial.

\section{Outcome measures}

Most trials $(163,94.2 \%)$ reported HRQoL and only 42 $(24.3 \%)$ reported hospital admissions or readmissions.

\section{Risk of bias of included studies}

Table 2 summarizes risk of bias. Few trials provided an adequate description of sequence generation or allocation concealment; and due to trials being unblinded, there was a high risk of bias for HRQoL outcomes.

\section{The effect of individual components of self-management interventions}

The effectiveness of individual components was established from interventions with only one component or where there was one additional component in the intervention compared to control. Only three trials of single components (exercise and action plans), two at a high risk of bias reported hospital admission rates, none reporting a significant effect (Table 3). In two trials of high risk of bias, breathing techniques (such 
Table I Characteristics of the trials and their populations

\begin{tabular}{|c|c|c|}
\hline Characteristic & $\mathbf{n}$ & $(\%)$ \\
\hline \multicolumn{3}{|l|}{ Setting } \\
\hline North America & 41 & 23.7 \\
\hline Europe & 82 & 47.4 \\
\hline Australasia & 18 & 10.4 \\
\hline Asia & 22 & 12.7 \\
\hline Other & 10 & 5.8 \\
\hline \multicolumn{3}{|l|}{ Sample size } \\
\hline$<50$ & 81 & 46.8 \\
\hline $50-99$ & 46 & 27.2 \\
\hline $100+$ & 46 & 26.2 \\
\hline \multicolumn{3}{|l|}{ Age (mean/years) } \\
\hline $50-59$ & II & 6.3 \\
\hline $60-69$ & 111 & 63.8 \\
\hline 70-79 & 29 & 16.7 \\
\hline $80+$ & 1 & 0.6 \\
\hline Not reported as mean age & 21 & 12.1 \\
\hline \multicolumn{3}{|l|}{ Males $(\mathrm{n}, \%)$} \\
\hline $1 \%-25 \%$ & 4 & 2.3 \\
\hline $26 \%-50 \%$ & 36 & 20.8 \\
\hline $51 \%-75 \%$ & 62 & 35.8 \\
\hline $75 \%-100 \%$ & 51 & 29.5 \\
\hline Not reported & 20 & 11.6 \\
\hline \multicolumn{3}{|l|}{ FEV,\% predicted (mean) } \\
\hline $50-79$ & 44 & 25.4 \\
\hline $30-49$ & 90 & 50.0 \\
\hline$<30$ & 5 & 2.9 \\
\hline Not reported as mean $\mathrm{FEV}_{1} \%$ predicted & 34 & 19.6 \\
\hline \multicolumn{3}{|l|}{ Recruited from: } \\
\hline Secondary care in-patient & 15 & 8.7 \\
\hline Secondary care outpatient/unspecified & 82 & 47.4 \\
\hline Emergency department & 1 & 0.6 \\
\hline Pulmonary rehabilitation program/referral & 21 & 12.1 \\
\hline Primary care & 9 & 5.2 \\
\hline Primary and secondary care & 3 & 1.7 \\
\hline Community & 3 & 1.7 \\
\hline Primary or secondary care and advertisement & 18 & 10.4 \\
\hline Not reported/unclear & 21 & 12.1 \\
\hline \multicolumn{3}{|l|}{ Duration of intervention (weeks) } \\
\hline$\leq 13$ & 118 & 65.3 \\
\hline $14-26$ & 28 & 16.2 \\
\hline $27+$ & 26 & 15.0 \\
\hline Unclear & 6 & 3.5 \\
\hline \multicolumn{3}{|l|}{ Mode of intervention delivery } \\
\hline Group & 62 & 35.8 \\
\hline Individual & 63 & 36.4 \\
\hline Mixed group and one-to-one & 24 & 13.9 \\
\hline Remote & 4 & 2.3 \\
\hline Unclear & 20 & 11.6 \\
\hline \multicolumn{3}{|l|}{ Time to last follow-up (weeks) } \\
\hline$\leq 13$ & 78 & 45.0 \\
\hline $14-26$ & 42 & 24.3 \\
\hline $27-52$ & 43 & 24.8 \\
\hline$>52$ & 8 & 4.6 \\
\hline Unclear & 2 & 1.2 \\
\hline \multicolumn{3}{|c|}{ Time from end of intervention to last follow-up (weeks) } \\
\hline 0 & 106 & 61.3 \\
\hline$\leq 13$ & 27 & 15.6 \\
\hline $14-26$ & 16 & 9.2 \\
\hline $27-52$ & 16 & 8.7 \\
\hline$>52$ & 3 & 1.7 \\
\hline Unclear & 6 & 3.5 \\
\hline
\end{tabular}

Note: $\mathrm{n}$ refers to number of studies. as yogic and diaphragmatic breathing) were associated with a significant and clinically important improvement in the SGRQ (MD 5.0, 95\% CI 4.06-5.94, $I^{2} 0 \%$ ), as was advice about fortification of food with milk powder $(10.10,95 \%$ CI 1.70-18.50). Single-component exercise interventions showed a significant and clinically important improvement in HRQoL at 3 months follow-up (SGRQ 4.87, 95\% CI 3.96-5.79, $I^{2} 0 \%$ ) although no significant effect was seen at later time points or when exercise was added to a self-management package. No benefits were observed for action plans or any other single component (Table 3; Figures S1-S3).

\section{The effectiveness of multicomponent self-management interventions}

There were many different multicomponent interventions and they were too diverse to create meaningful groups. Overall, multicomponent interventions did not result in reduction in hospital admissions (Table 4; Figure S4), but were on average associated with improvements in HRQoL at all-time points (Table 5 and Figure 2; Figure S5), although there was high between-study heterogeneity in effect.

A group of multicomponent interventions which contained supervised exercise resulted in significant effects on HRQoL up to 6 months follow-up, but were not sustained and heterogeneity was very high (Figures S6 and S7). Significant effects on HRQoL were also observed for multicomponent interventions containing more limited exercise counseling, but those without any exercise support or counseling demonstrated no improvement in HRQoL (Figures S8-S10).

Table 2 Summary of risk of bias

\begin{tabular}{|c|c|c|c|c|}
\hline \multirow[t]{2}{*}{ Risk of bias } & \multirow{2}{*}{$\frac{\text { Low }}{\mathrm{n} \%}$} & \multirow{2}{*}{$\frac{\text { High }}{n \%}$} & \multirow{2}{*}{$\frac{\text { Unclear }}{n \%}$} & \multirow[t]{2}{*}{ Total } \\
\hline & & & & \\
\hline \multirow[t]{2}{*}{ Sequence generation } & 66 & 0 & 107 & 173 \\
\hline & 38.2 & 0 & 62.8 & \\
\hline \multirow[t]{2}{*}{ Allocation concealment } & 27 & I & 145 & 173 \\
\hline & 15.6 & 0.6 & 83.8 & \\
\hline \multirow[t]{2}{*}{ Blinding of HRQoL outcome } & 33 & 117 & 23 & 173 \\
\hline & 19.1 & 67.6 & 13.3 & \\
\hline \multirow[t]{2}{*}{ Blinding of admission outcome } & 44 & 0 & I & 45 \\
\hline & 97.8 & 0 & 2.2 & \\
\hline \multirow[t]{2}{*}{ Incomplete outcome data } & 46 & 82 & 45 & 173 \\
\hline & 26.6 & 50.0 & 26.0 & \\
\hline \multirow[t]{2}{*}{ Selective outcome reporting } & 54 & 2 & 117 & 173 \\
\hline & 31.2 & 1.2 & 67.6 & \\
\hline \multirow[t]{2}{*}{ Other biases } & 44 & 86 & 43 & 173 \\
\hline & 25.4 & 49.7 & 24.9 & \\
\hline
\end{tabular}

Notes: $\mathrm{n}$ refers to number of studies. Other biases include: only presenting the baseline characteristics of participants who completed follow-up; baseline differences between study groups; limited baseline characteristics reported.

Abbreviation: HRQoL, health-related quality of life. 


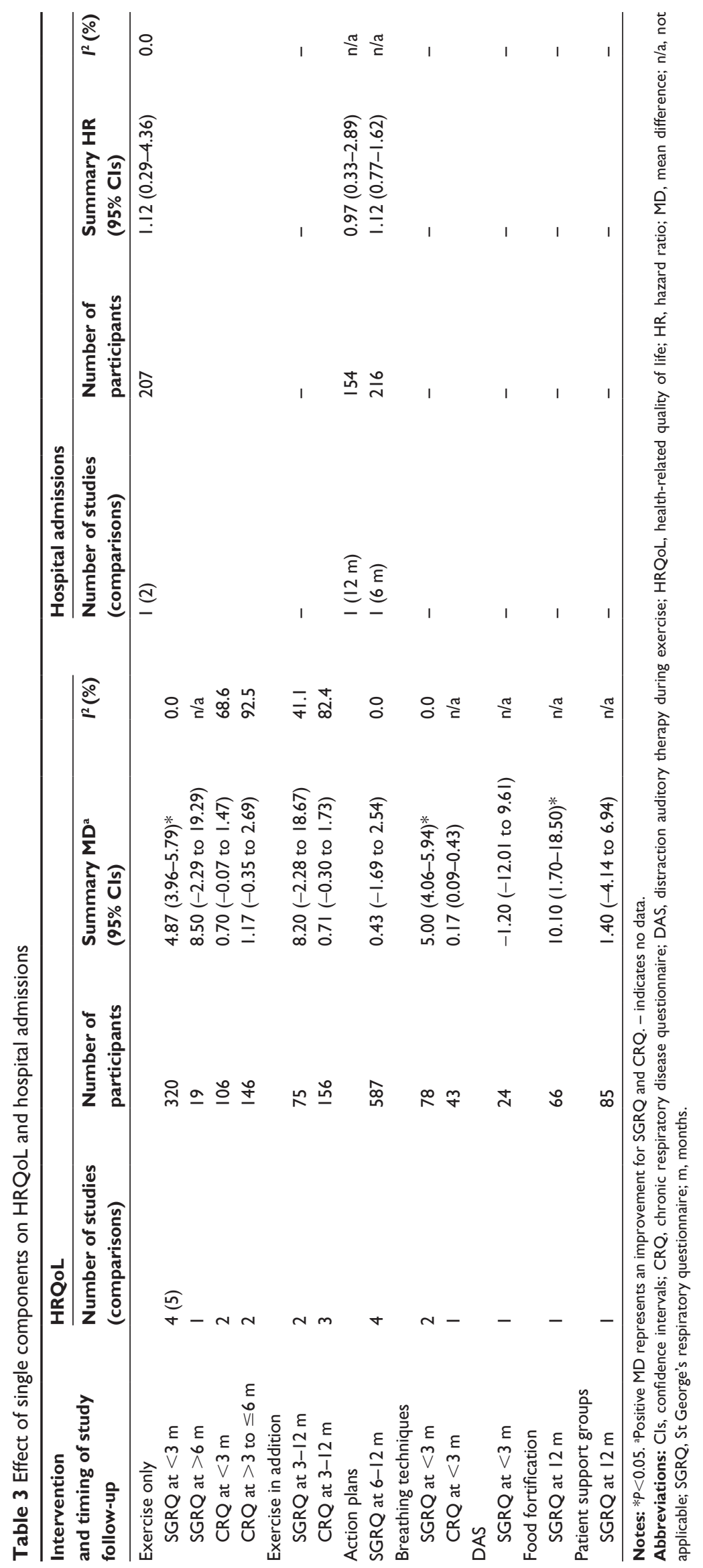




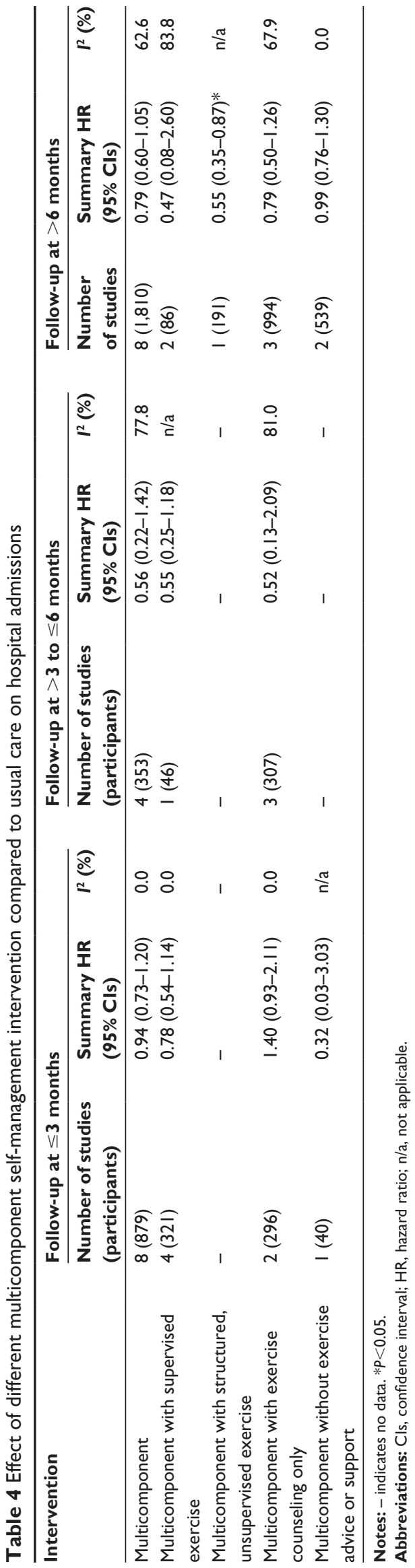

\section{Publication bias}

The four funnel plots of meta-analyses with at least ten studies show very strong evidence of publication bias consistent with an absence of smaller studies with negative outcomes.

\section{Discussion}

This systematic review explored the components and delivery of self-management interventions to try to identify optimal mode of delivery and make-up of such interventions on hospital admission and HRQoL. Few interventions reduced hospital admissions, with only one analysis of one trial having a significant effect. Many different interventions improved HRQoL, particularly in the shorter term. It was unfortunately not possible to describe a package of effective elements, although exercise and dyspnea management seem important. This is supported by recent systematic reviews which report an association between physical activity and exacerbations, mortality and HRQoL, ${ }^{14}$ and similar HRQoL outcomes in exercise-only and multicomponent pulmonary rehabilitation. ${ }^{15}$

\section{Comparison with the existing literature}

Through mapping self-management interventions and their individual components, we were able to show the range of interventions, with differing components, delivered in a variety of ways. Almost all multicomponent interventions included exercise, and this was also the most common element in single-/two-component interventions.

Education is an important element of COPD selfmanagement interventions; it was included in almost half the studies in this review. However, education is generally not effective by itself ${ }^{16}$ it requires combination with active, behavioral strategies, but it was frequently unclear to what extent these techniques were used. The use of a taxonomy of behavior change to describe the self-management interventions would enable their relative contributions to be ascertained. ${ }^{17}$

There were few studies which evaluated either individual components compared with usual care, or addition of an individual component to a wider package of care. Exploration of single-component interventions is important, as it may be easier for participants to focus on a single behavioral change rather than multiple.

We identified no significant effect on admissions or HRQoL with action plans, which supports previous evidence. $^{18}$

We have reported the effects of exercise-only/exercise with dyspnea management interventions compared to usual care. 


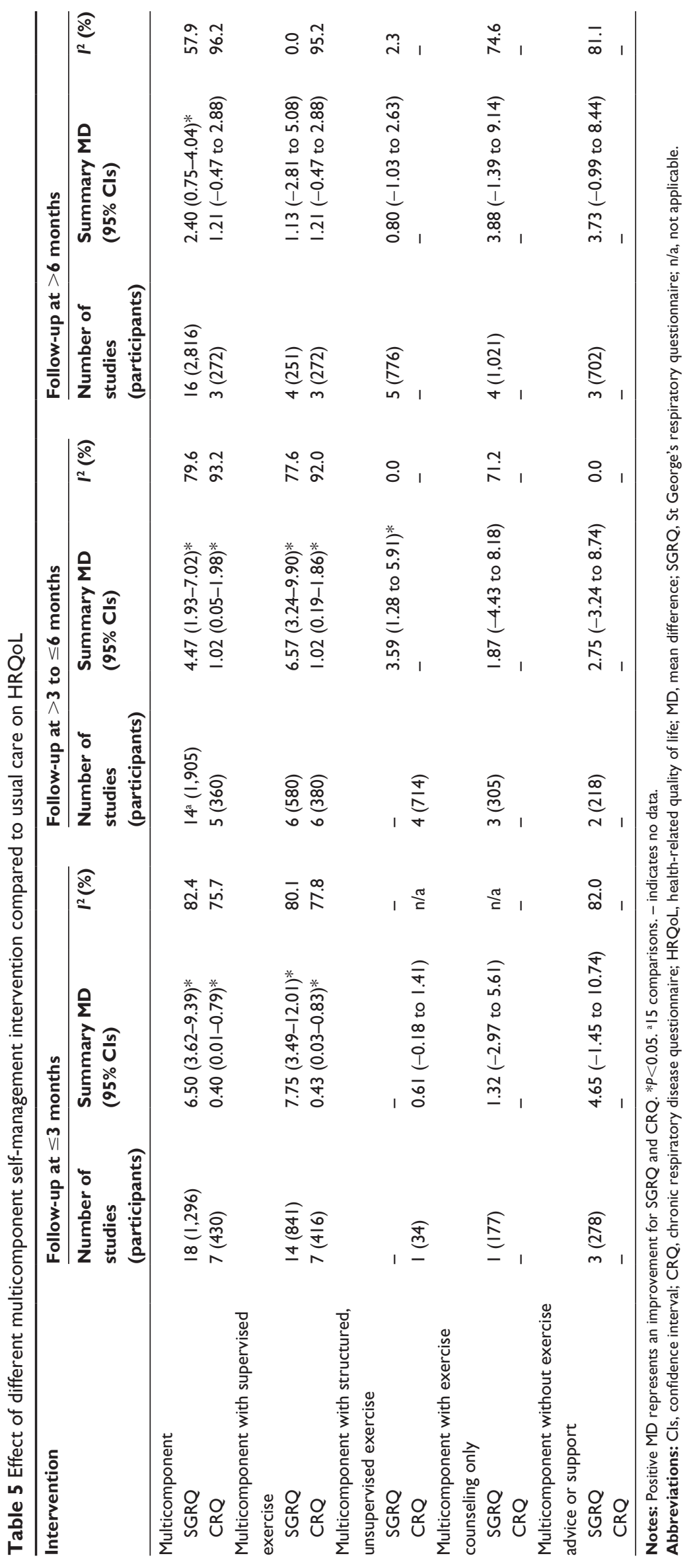




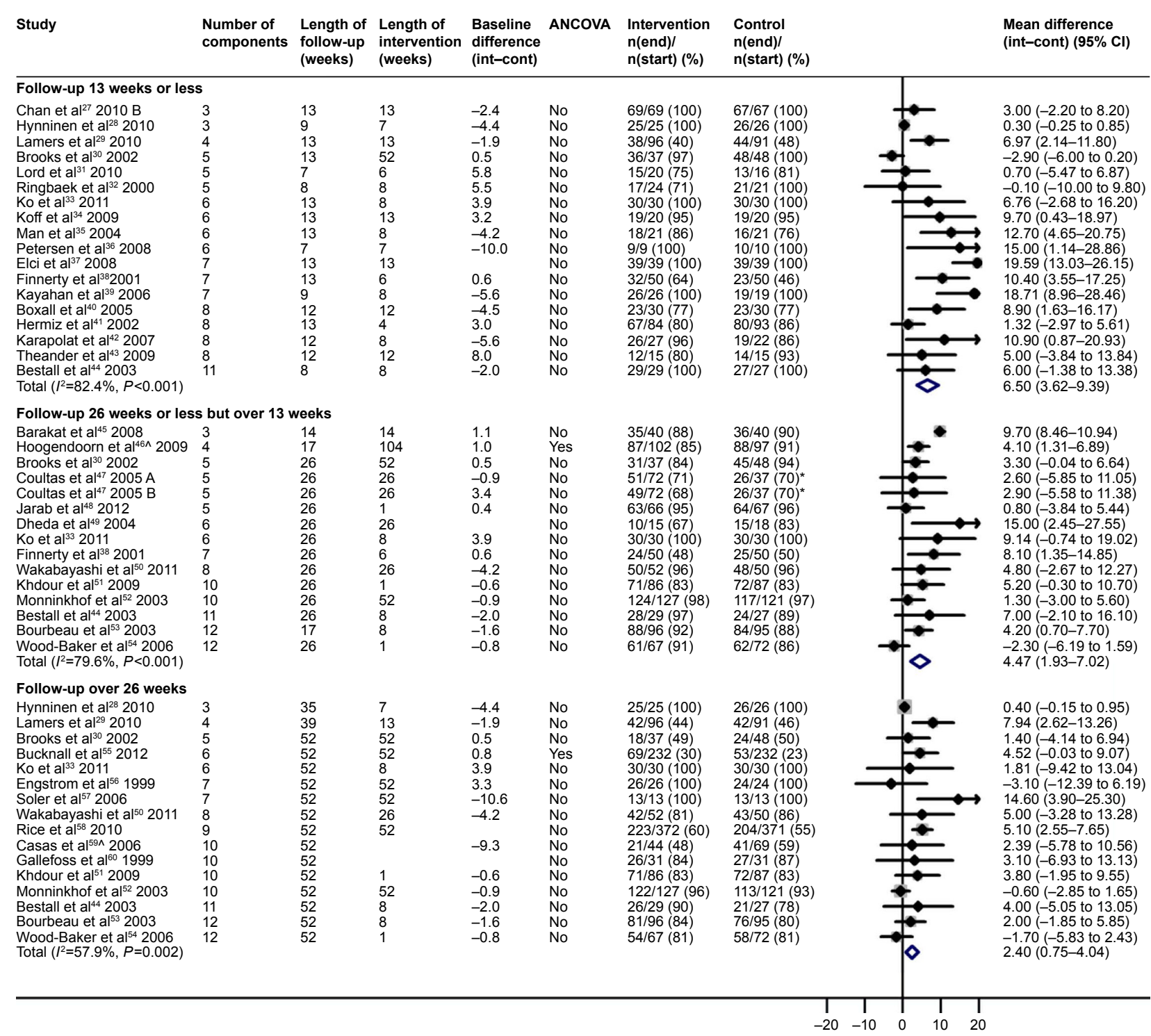

Mean difference (effect size $>0$ favors intervention)

Figure 2 HRQoL (SGRQ) outcomes for multicomponent self-management intervention versus usual care.

Notes: ^Indicates that several papers are represented by this lead publication. $\mathrm{A}=$ nurse-assisted collaborative management vs $\mathrm{UC}$. $\mathrm{B}=$ nurse-assisted medical management vs $\mathrm{UC}$. Abbreviations: ANCOVA, analysis of covariance; Cl, confidence interval; HRQoL, health-related quality of life; Int, intervention group; Cont, control group; SGRQ, St George's respiratory questionnaire; UC, usual care.

In trials with follow-up at 3 months or less, there was a clinically and statistically significantly higher HRQoL in the self-management group, but due to few trials reporting admissions or HRQoL with longer follow-up, we have no evidence of an effect after this short period.

Our meta-analysis indicates that on average multicomponent, self-management interventions have a positive effect on HRQoL. Our summary estimates were larger than the minimal clinically important difference for SGRQ at follow-up to 6 months for multicomponent interventions and at all follow-up points for the CRQ. ${ }^{19}$ However, we did find considerable heterogeneity, making it unclear which particular interventions and settings work best.
A recent Cochrane review reported significantly fewer hospital admissions (OR 0.60; 95\% CI 0.40-0.89, six studies) and better HRQoL (MD in SGRQ $-3.51,95 \%$ CI -5.37 to -1.65 , ten studies) in patients allocated to selfmanagement, but excluding pulmonary rehabilitation. ${ }^{20}$ This effect was larger than seen in a previous review of limited self-management education alone. ${ }^{21}$ It is consistent with the effects of the more supported interventions in our review.

Several systematic reviews have addressed effectiveness of disease management. ${ }^{22,23}$ A Cochrane review of integrated care reported a difference of 3.71 points on the SGRQ (95\% CI 1.6, 5.8) favoring the intervention group 
and reduction in respiratory admissions (OR 0.68, 95\% CI $0.47,0.99) .{ }^{22}$ Given this recent report, we did not repeat this analysis.

Our analysis of self-management interventions with supervised exercise is similar to that of pulmonary rehabilitation programs. ${ }^{15}$ The McCarthy review found a similar effect size at our follow-up points up to 6 months, but only provided one follow-up point. We report an attenuated effect after 1 year. We had higher heterogeneity, which may reflect our wider inclusion criteria and have been able to extend their review by reporting hospital admissions. Our study differs from many other systematic reviews ${ }^{14,20,22}$ in reporting follow-up at three time points. Our findings of a possibly attenuation of effect are important and highlight the need for follow-up to 1 year or more and for interventions to include behavioral change strategies that will lead to long-term behavior change.

All our included trials delivered self-management to patients in groups or one-to-one. A large UK-based cluster randomized trial, published after our search was completed, supported primary care practitioners to embed self-management support into everyday practice, ${ }^{24}$ but did not find statistically significant improvements in self-efficacy, HRQoL or shared decision-making (see additional Supplementary materials).

Our findings suggest that self-management support improves HRQoL in people with COPD. The mechanism of action of this improvement is likely to be due to a reduction in dyspnea and distress from dyspnea as a result of exercise and breathing techniques, reduced fatigue, improved mental health from increased physical activity, an altered perception about limitations in daily activities, and an increased confidence in management of their condition. ${ }^{25}$ These may also lead to increased confidence in taking part in social activities.

\section{Strengths and limitations}

This is the largest systematic review of self-management for COPD; searching was systematic with no exclusions by language or publication date. We used an extensive data extraction form to extract directly and, where not reported, indirectly calculate statistical results for intervention effects of interest. This allowed us to incorporate a larger number of studies in meta-analysis than previous reviews. Heterogeneity was apparent in most meta-analyses in this study, but none of the possible causes we explored were explained. Possible causes of heterogeneity include the usual care received by the control groups, severity of COPD, intervention differences in terms of components, duration, intensity, setting, mode of delivery, and professional backgrounds of the people delivering the intervention.

Limitations result from heterogeneity of both the interventions and comparison groups, and general poor standard of reporting and conduct of many identified trials. As many trials used a "usual care" comparator, participants were generally not blinded to their allocation. This may have led to an attention effect, where participants in the active intervention arm have a more positive experience and often more social support through group-based activities. The heterogeneity meant that we were unable to perform indirect comparisons, which had been our intention. We included trials with any self-management components, which resulted in $16 \%$ of included trials being of a single self-management component. There is no agreed definition of self-management, but previous reviews have required self-management interventions to be multicomponent for inclusion. ${ }^{20}$ Given that the focus of this review was to try to identify the most effective components of interventions to facilitate self-management of health care behaviors, it was important to include singlecomponent self-management interventions in this review. We also found strong evidence of possible publication bias. The publication bias is a concern; however, the asymmetry may be due to systematic associations between sample size and other characteristics that impact on outcome, such as proactive support or group-based provision. The search was completed in 2012, so more recent literature may have been published. In addition, "usual care" has improved in recent years, with most hospitals in the UK now offering education as standard care; this may diminish the observed effect of self-management in more recent trials. Furthermore, due to the large literature identified we confined our outcomes to HRQoL reported using the SGRQ and CRQ and all-cause hospital admissions. This will have led to a potential loss of subtlety in the findings and interpretation as we can only comment on all-cause admissions. It may be that certain intervention components may have a greater effect on respiratory admissions, for example, pulmonary rehabilitation leads to a reduction in respiratory admissions. ${ }^{26}$

We planned to undertake full independent double data extraction on all papers, but due to the large number of eligible papers only one person extracted the characteristics and outcomes, with a $20 \%$ check of the outcome data and $100 \%$ check for key characteristics. To ensure consistency, the same person categorized the components in all trials. In extracting HRQoL outcome data, we focused on diseasespecific measures (SGRQ and CRQ), and have not reported 
the generic HRQoL outcomes as a wide variety of these were reported in a small number of trials.

Hospital admissions were reported in several different ways. We chose the rate of first admission because there were more data available; however, it is not clear how the effect of interventions would vary if all admissions could be considered. We were unable to separate out all-cause and respiratory admissions in many cases, so have reported all-cause admissions, which may be less amenable to change as a result of self-management interventions.

Included trials were set in 21 countries, suggesting that our findings can be generalized across a range of different health care settings. We did not explore the effect of the standard level of COPD care as potential cause of heterogeneity as it was often poorly described, but it may be an important factor. Most trial participants were recruited from secondary care, and participants generally had moderate/ severe COPD, thus our findings may not be generalized well to populations with milder COPD managed in primary care. In addition, trials may recruit participants who are more affluent or have a higher educational level than the general population. Given the fundamental role of self-efficacy in many self-management interventions, the participant representativeness is key.

\section{Implications for future research or clinical practice}

While overall self-management support for COPD appears to be associated with improvements in HRQoL, there is only evidence for an effect on hospital admissions in the most supported subgroup. The considerable inconsistency in outcomes requires additional research, but future trials need to be larger, better designed and reported, with longer follow-up after the end of the intervention and clearer descriptions of the interventions describing the behavioral change components employed. Future evidence syntheses would be greatly aided by consistent reporting of hospital admissions and the use of a single patient-reported outcome for HRQoL. An individual patient data meta-analysis of high-quality trials might shed more light on which individual components of self-management are most effective.

\section{Acknowledgments}

The authors thank Simon Stevens for his administrative support. All the people who kindly gave their time to help translate articles are as follows: Yumiko Akiya, Dom Barkos, Susan Bayliss, Matthew Blackburn, Yumi Chen, Jennifer Choi, Karin Diaconu, Janine Dretzke,
Maxwell Feltham, Ditte Hedegaard, Boris Kysela, Antje Lindenmeyer, Kinga Malottki, Cristina Peñaloza, and Amanda Zhang.

\section{Author contributions}

$\mathrm{KJ}$ and REJ conceived the study, KJ, REJ, RDR, PA, DAF, and DJM contributed to the protocol, SEB advised on and performed search strategies, KJ, SM, REJ, NRH, DJM, PA, and AMT contributed to study selection, SM led the development of a risk of bias and data extraction tools, SM, NRH, and EJB extracted results, SM, EJB, NRH, DJM, and KJ undertook the risk of bias assessment, SM, MJP, and RDR coordinated and undertook some data extraction and/or calculation of effect estimates, RDR advised on statistical and reviewing methods and supervised statistical analyses, AJS undertook the statistical analyses, KJ oversaw the analyses, SJS, DAF, and AMT provided clinical input, KJ with input from REJ and RDR wrote and edited the paper. All authors contributed to the paper and commented on the final version.

\section{Disclosure}

AMT reports grants from University of Birmingham/ National Institute for Health Research (NIHR), during the conduct of the study; REJ was in receipt of an NIHR postdoctoral research fellowship (pdf/01/2008/023) during the conduct of the study; KJ, DAF, REJ, PA, and SJS are investigators on an NIHR SPCR funded trial of self-management for COPD; SJS reports that the University Hospitals of Leicester National Health Service trust holds the IP for a self-management manual for COPD. REJ was funded by NIHR Health Technology Assessment Programme $(10 / 44 / 01)$. KJ is part-funded by the National Institute for Health Research (NIHR) Collaborations for Leadership in Applied Health Research and Care (CLAHRC) West Midlands. SJS is part-funded by the CLAHRC-East Midlands. Malcolm Price was supported by funding from a multivariate meta-analysis grant from the MRC Methodology Research Programme (grant reference number: MR/ J013595/1). The views and opinions expressed therein are those of the authors and do not necessarily reflect those of the Health Technology Assessment programme, NIHR, National Health Service, or the Department of Health. Any errors are the responsibility of the authors. The other authors report no other conflicts of interest in this work.

\section{References}

1. Barlow J, Wright C, Sheasby J, Turner A, Hainsworth J. Self-management approaches for people with chronic conditions: a review. Patient Educ Couns. 2002;48:177-187. 
2. Effing TW, Bourneau J, Vercoulen J, et al. Self-management programmes for COPD: moving forward. Chron Respir Dis. 2012;9:27-35.

3. Department of Health (England). An outcomes strategy for people with chronic obstructive pulmonary disease (COPD) and asthma in England. Department of Health; 2011. Available from: https://www.gov.uk/ government/uploads/system/uploads/attachment_data/file/216139/ dh_128428.pdf. Date last updated July 18, 2011. Accessed February 17, 2015.

4. Britton M. The burden of COPD in the UK: results from the confronting COPD survey. Respir Med. 2003;97(Supplement 3):S71-S79.

5. Bourbeau J, van der PJ. Promoting effective self-management programmes to improve COPD. Eur Respir J. 2009;33:461-463.

6. Wagg K. Unravelling self-management for COPD: what next? Chron Respir Dis. 2012;9:5-7.

7. Higgins JPT, Green S. Chapter 8: Assessing risk of bias in included studies. Cochrane Handbook for Systematic Reviews of Interventions Version 5.1.0; 2011 [updated March 2011]. Available from: http:// handbook.cochrane.org/chapter_8/8_assessing_risk_of_bias_in_ included_studies.htm. Accessed December 7, 2015.

8. Parmar MK, Torri V, Stewart L. Extracting summary statistics to perform meta-analyses of the published literature for survival endpoints. Stat Med. 1998;17:2815-2834.

9. Perneger TV. Estimating the relative hazard by the ratio of logarithms of event-free proportions. Contemp Clin Trials. 2008;29:762-766.

10. Sweeting MJ, Sutton AJ, Lambert PC. What to add to nothing? Use and avoidance of continuity corrections in meta-analysis of sparse data. Stat Med. 2004;23:1351-1375.

11. DerSimonian R, Laird N. Meta-analysis in clinical trials. Control Clin Trials. 1986;7:177-188.

12. Higgins JP, Thompson SG, Deeks JJ, Altman DG. Measuring inconsistency in meta-analyses. BMJ. 2003;327:557-560.

13. Higgins JPT, Green S. Chapter 16: Special Topics in Statistics. Cochrane Handbook for Systematic Reviews of Interventions. Version 5.1.0; 2011 [updated March 2011]. Available from: http://handbook.cochrane.org/ chapter_16/16_5_4_how_to_include_multiple_groups_from_one_ study.htm. Accessed December 7, 2015.

14. Gimeno-Santos E, Frei A, Steurer-Stey C, et al. Determinants and outcomes of physical activity in patients with COPD: a systematic review. Thorax. 2014;(8):731-739.

15. McCarthy B, Casey D, Devane D, Murphy K, Murphy E, Lacasse Y. Pulmonary rehabilitation for chronic obstructive pulmonary disease. Cochrane Database Syst Rev. 2015;(2):CD003793.

16. Gibson PG, Coughlan J, Wilson AJ, et al. Limited (information only) patient education programs for adults with asthma. Cochrane Database Syst Rev. 2000;(2):CD001005.

17. Abraham C, Michie S. A taxonomy of behavior change techniques used in interventions. Health Psychol. 2008;27(3):379-387.

18. Walters JA, Turnock AC, Walters EH, Wood-Baker R. Action plans with limited patient education only for exacerbations of chronic obstructive pulmonary disease. Cochrane Database Syst Rev. 2010;(5): CD005074.

19. Jaeschke R, Singer J, Guyatt GH. Measurement of health status. Ascertaining the minimal clinically important difference. Control Clin Trials. 1989;10:407-415.

20. Zwerink M, Brusse-Keizer M, van der Valk PD, et al. Self management for patients with chronic obstructive pulmonary disease. Cochrane Database Syst Rev. 2014;(3):CD002990.

21. Effing T, Monninkhof EM, van der Valk PD, et al. Self-management education for patients with chronic obstructive pulmonary disease. Cochrane Database Syst Rev. 2007;(4):CD002990.

22. Kruis AL, Smidt N, Assendelft-Willem JJ, et al. Integrated disease management interventions for patients with chronic obstructive pulmonary disease. Cochrane Database Syst Rev. 2013;(10):CD009437.

23. Peytremann-Bridevaux I, Staeger P, Bridevaux PO, Ghali WA, Burnand B. Effectiveness of chronic obstructive pulmonary diseasemanagement programs: systematic review and meta-analysis. Am J Med. 2008;121:433-443.
24. Kennedy A, Bower P, Reeves D, et al. Implementation of self management support for long term conditions in routine primary care settings: cluster randomised controlled trial. BMJ. 2013;346:f2882.

25. Kaptein Ad A, Fischer MJ, Scharloo M. Self-management in patients with COPD: theoretical context, content, outcomes and integration into clinical care. Int J COPD. 2014;9:907-917.

26. National Institute of Health and Care Excellence. Services for people with chronic obstructive pulmonary disease. NICE Commissioning Guides [CMG43]. October 2011. Available from: http://www.nice. org.uk/guidance/cmg43. Accessed December 7, 2015.

27. Chan AW, Lee A, Suen LK, Tam WW. Effectiveness of a Tai chi Qigong program in promoting health-related quality of life and perceived social support in chronic obstructive pulmonary disease clients. Qual Life Res. 2010;19(5):653-664.

28. Hynninen MJ, Bjerke N, Pallesen S, Bakke PS, Nordhus IH. A randomized controlled trial of cognitive behavioral therapy for anxiety and depression in COPD. Respir Med. 2010;104(7):986-994.

29. Lamers $\mathrm{F}$, Jonkers CC, Bosma $\mathrm{H}$, et al. Improving quality of life in depressed COPD patients: effectiveness of a minimal psychological intervention. COPD. 2010;7(5):315-322.

30. Brooks D, Krip B, Mangovski-Alzamora S, Goldstein RS. The effect of postrehabilitation programmes among individuals with chronic obstructive pulmonary disease. Eur Respir J. 2002;20(1):20-29.

31. Lord VM, Cave P, Hume VJ, et al. Singing teaching as a therapy for chronic respiratory disease - a randomised controlled trial and qualitative evaluation. BMC Pulmonary Medicine. 2010;10:41.

32. Ringbaek TJ, Broendum E, Hemmingsen L, et al. Rehabilitation of patients with chronic obstructive pulmonary disease. Exercise twice a week is not sufficient! Respir Med. 2000;94(2):150-154.

33. Ko FW, Dai DL, Ngai J, et al. Effect of early pulmonary rehabilitation on health care utilization and health status in patients hospitalized with acute exacerbations of COPD. Respirology. 2011;16(4):617-624.

34. Koff PB, Jones RH, Cashman JM, Voelkel NF, Vandivier RW. Proactive integrated care improves quality of life in patients with COPD. Eur Respir J. 2009;33(5):1031-1038.

35. Man WD, Polkey MI, Donaldson N, Gray BJ, Moxham J. Community pulmonary rehabilitation after hospitalisation for acute exacerbations of chronic obstructive pulmonary disease: randomised controlled study. BMJ. 2004;329(7476): 1209.

36. Petersen AM, Mittendorfer B, Magkos F, Iversen M, Pedersen BK. Physical activity counteracts increased whole-body protein breakdown in chronic obstructive pulmonary disease patients. Scand J Med Sci Sports. 2008;18(5):557-564.

37. Elci A, Borekci S, Ovayolu N, Elbek O. The efficacy and applicability of a pulmonary rehabilitation programme for patients with COPD in a secondary-care community hospital. Respirology. 2008;13(5):703-707.

38. Finnerty JP, Keeping I, Bullough I, Jones J. The effectiveness of outpatient pulmonary rehabilitation in chronic lung disease: a randomized controlled trial. Chest. 2001;119(6):1705-1710.

39. Kayahan B, Karapolat H, Atyntoprak E, Atasever A, Ozturk O. Psychological outcomes of an outpatient pulmonary rehabilitation program in patients with chronic obstructive pulmonary disease. Respir Med. 2006;100(6):1050-1057.

40. Boxall AM, Barclay L, Sayers A, Caplan GA. Managing chronic obstructive pulmonary disease in the community. A randomized controlled trial of home-based pulmonary rehabilitation for elderly housebound patients. J Cardiopulm Rehabil. 2005;25(6):378-385.

41. Hermiz O, Comino E, Marks G, et al. Randomised controlled trial of home based care of patients with chronic obstructive pulmonary disease. BMJ. 2002;325(7370):938.

42. Karapolat H, Atasever A, Atamaz F, et al. Do the benefits gained using a short-term pulmonary rehabilitation program remain in COPD patients after participation? Lung. 2007;185(4):221-225.

43. Theander K, Jakobsson P, Jorgensen N, Unosson M. Effects of pulmonary rehabilitation on fatigue, functional status and health perceptions in patients with chronic obstructive pulmonary disease: a randomized controlled trial. Clinical Rehabilitation. 2009;23(2):125-136. 
44. Bestall JC, Paul EA, Garrod R, et al. Longitudinal trends in exercise capacity and health status after pulmonary rehabilitation in patients with COPD. Respir Med. 2003;97(2):173-180.

45. Barakat S, Michele G, George P, Nicole V, Guy A. Outpatient pulmonary rehabilitation in patients with chronic obstructive pulmonary disease. Int J Chron Obstruct Pulmon Dis. 2008;3(1):155-162.

46. Hoogendoorn M, van Wetering CR, Schols AM, Rutten-van Molken MP. Self-report versus care provider registration of healthcare utilization: impact on cost and cost-utility. Int J Technol Assess Health Care. 2009;25(4):588-595.

47. Coultas D, Frederick J, Barnett B, Singh G, Wludyka P. A randomized trial of two types of nurse-assisted home care for patients with COPD Chest. 2005;128(4):2017-2024.

48. Jarab AS, Alqudah SG, Khdour M, Shamssain M, Mukattash TL. Impact of pharmaceutical care on health outcomes in patients with COPD. Int J Clin Pharm. 2012;34(1):53-62.

49. Dheda K, Crawford A, Hagan G, Roberts CM. Implementation of British Thoracic Society guidelines for acute exacerbation of chronic obstructive pulmonary disease: Impact on quality of life. Postgrad Med J. 2004;80(941):169-171.

50. Wakabayashi R, Motegi T, Yamada K, et al. Efficient integrated education for older patients with chronic obstructive pulmonary disease using the Lung Information Needs Questionnaire. Geriatr Gerontol Int. 2011; 11(4):422-430.

51. Khdour MR, Kidney JC, Smyth BM, McElnay JC. Clinical pharmacyled disease and medicine management programme for patients with COPD. Br J Clin Pharmacol. 2009;68(4):588-598.

52. Monninkhof E, van der Valk P, van der Palen J, van Herwaarden C, Zielhuis G. Effects of a comprehensive self-management programme in patients with chronic obstructive pulmonary disease. Eur Respir J. 2003;22(5):815-820.
53. Bourbeau J, Julien M, Maltais F, et al. Reduction of hospital utilization in patients with chronic obstructive pulmonary disease: a disease-specific self-management intervention. Arch Intern Med. 2003; 163(5):585-591.

54. Wood-Baker R, McGlone S, Venn A, Walters EH. Written action plans in chronic obstructive pulmonary disease increase appropriate treatment for acute exacerbations. Respirology. 2006;11(5):619-626.

55. Bucknall CE, Miller G, Lloyd SM, et al. Glasgow supported selfmanagement trial (GSuST) for patients with moderate to severe COPD: randomised controlled trial. BMJ. 2012;344:e1060.

56. Engstrom CP, Persson LO, Larsson S, Sullivan M. Long-term effects of a pulmonary rehabilitation programme in outpatients with chronic obstructive pulmonary disease: a randomized controlled study. Scand J Rehabil Med. 1999;31(4):207-213.

57. Soler JJ, Martinez-Garcia MA, Roman P, et al. [Effectiveness of a specific program for patients with chronic obstructive pulmonary disease and frequent exacerbations]. [Spanish]. Archivos de Bronconeumologia. 2006;42(10):501-508.

58. Rice KL, Dewan N, Bloomfield HE, et al. Disease management program for chronic obstructive pulmonary disease: a randomized controlled trial. Am J Respir Crit Care Med. 2010;182(7):890-896.

59. Casas A, Troosters T, Garcia-Aymerich J, et al. Integrated care prevents hospitalisations for exacerbations in COPD patients. Eur Respir J. 2006; 28(1):123-130.

60. Gallefoss F, Bakke PS, Rsgaard PK. Quality of life assessment after patient education in a randomized controlled study on asthma and chronic obstructive pulmonary disease. Am J Respir Crit Care Med. $1999 ; 159(3): 812-817$. 


\section{Supplementary materials}

Table SI Definitions of components of self-management

\begin{tabular}{|c|c|}
\hline Component & Broad inclusion/definition \\
\hline Disease knowledge & $\begin{array}{l}\text { Education about disease, disease management, treatments, self-management, chronic illness, activities } \\
\text { of daily life, end of life, self-care tips, travel, and COPD }\end{array}$ \\
\hline Self-management unspecified & Self-management education/skills \\
\hline Respiratory muscle training & Inspiratory muscle training, expiratory muscle training (pressure, threshold, and resistance devices) \\
\hline Action planning & Managing exacerbations, coping plan, management of COPD symptoms, recognizing when to call a doctor \\
\hline Breathing management and techniques & $\begin{array}{l}\text { Breathing exercises, breathing retraining, respiratory biofeedback, managing breathlessness and coping } \\
\text { with triggers for breathlessness, tai chi, vocal exercises }\end{array}$ \\
\hline Smoking cessation & Advice, counseling, groups, interventions to help reduce/quite smoking as required \\
\hline Medication/adherence & $\begin{array}{l}\text { Information about medication and adherence, promoting adherence (pharmacological or } \\
\text { nonpharmacological) }\end{array}$ \\
\hline Bronchial hygiene techniques & Postural drainage/coughing technique \\
\hline Nutrition & Advice, counseling, groups, supplements as required \\
\hline Psychological intervention & $\begin{array}{l}\text { Psychosocial support, cognitive behavioral therapy, cognitive training, relaxation (including exercises, } \\
\text { eg, progressive muscle relaxation), stress management, general goal setting, mood disturbance, handling } \\
\text { emotions (how to cope with the disease), psychosocial problems associated with respiratory disability, } \\
\text { self-talk and panic control, health qigong }\end{array}$ \\
\hline Preventative & Avoiding exacerbations, pollution and environmental hazards, managing infections, and personal hygiene \\
\hline Inhaler technique and use & Assessing inhaler technique, teaching correct use, and handling of inhalers \\
\hline Energy conservation & Pacing and good posture, home modifications and activities of daily living, work simplification \\
\hline Support groups/patient empowerment & $\begin{array}{l}\text { Peer support self-help groups/networks, eg, Breathe Easy, developing confidence to negotiate } \\
\text { with clinicians }\end{array}$ \\
\hline Exercise - strength & Upper limb, lower limb strength/resistance exercises \\
\hline Exercise - aerobic & Cycling, walking, stair climbing as aerobic/endurance exercises \\
\hline Exercise - other & Flexibility and balance exercises, sham training, unspecified exercises \\
\hline Enhanced access/care & $\begin{array}{l}\text { Access to health professionals, access to call center/hotline, health professional home visits and/or } \\
\text { telephone support }\end{array}$ \\
\hline Other & Any miscellaneous uncommon components, eg, sleep or other symptom control \\
\hline Usual care & Usual medications and visits to general practitioner or routine secondary care \\
\hline
\end{tabular}




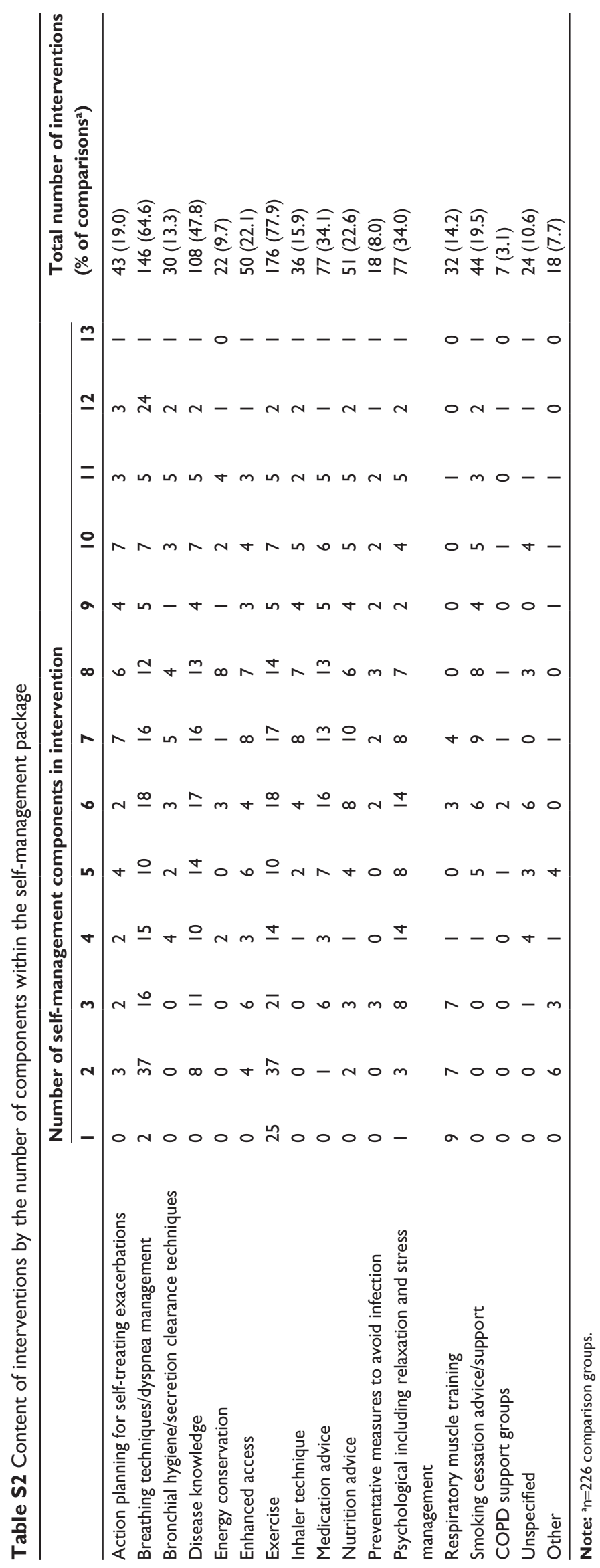




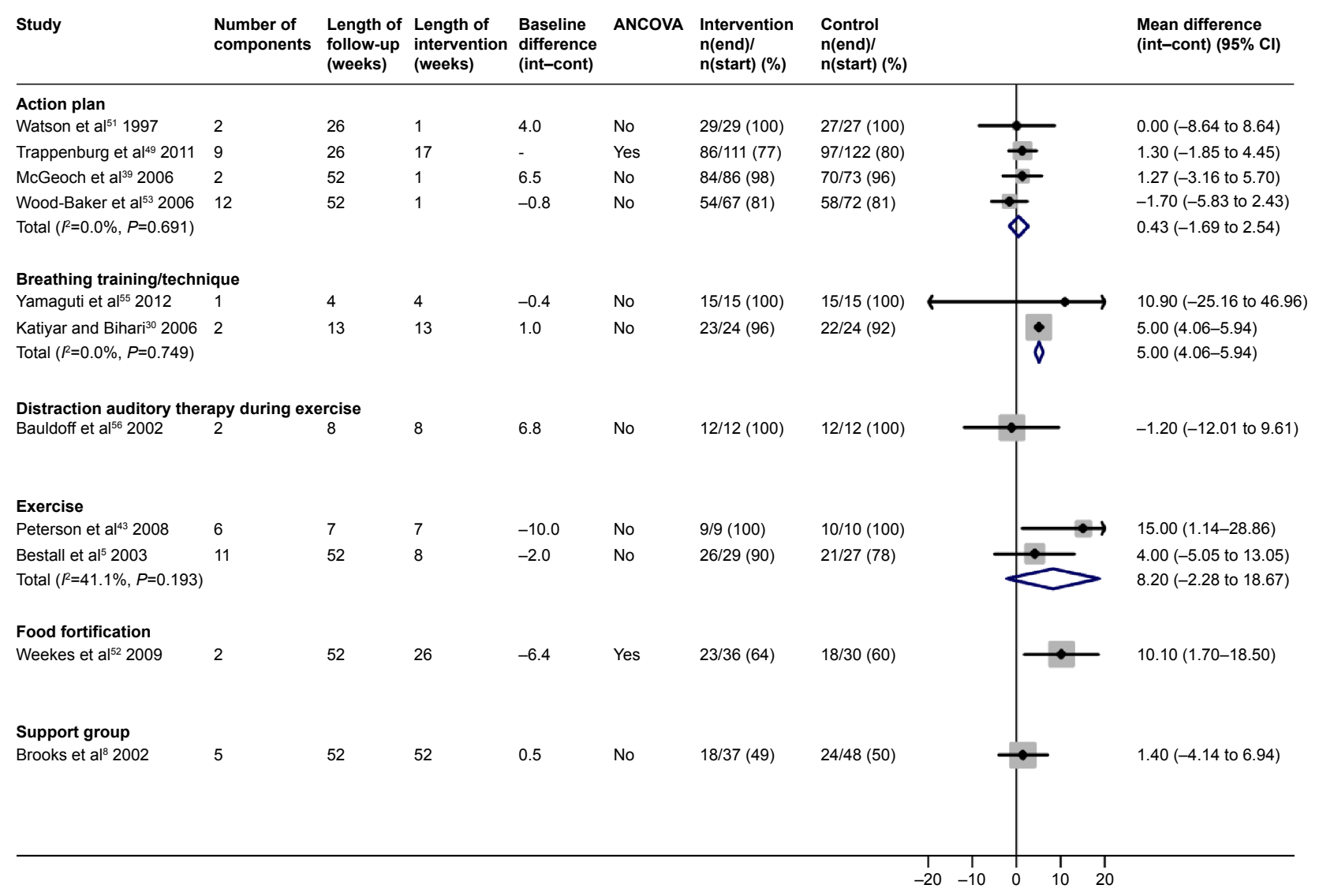

\section{Mean difference (effect size $>0$ favors intervention)}

Figure SI HRQoL (SGRQ) at final follow-up for comparisons assessing the effects of one additional component of self-management.

Abbreviations: ANCOVA, analysis of covariance; CI, confidence interval; HRQoL, health-related quality of life; SGRQ, St George's respiratory questionnaire; Int, intervention group; Cont, control group.

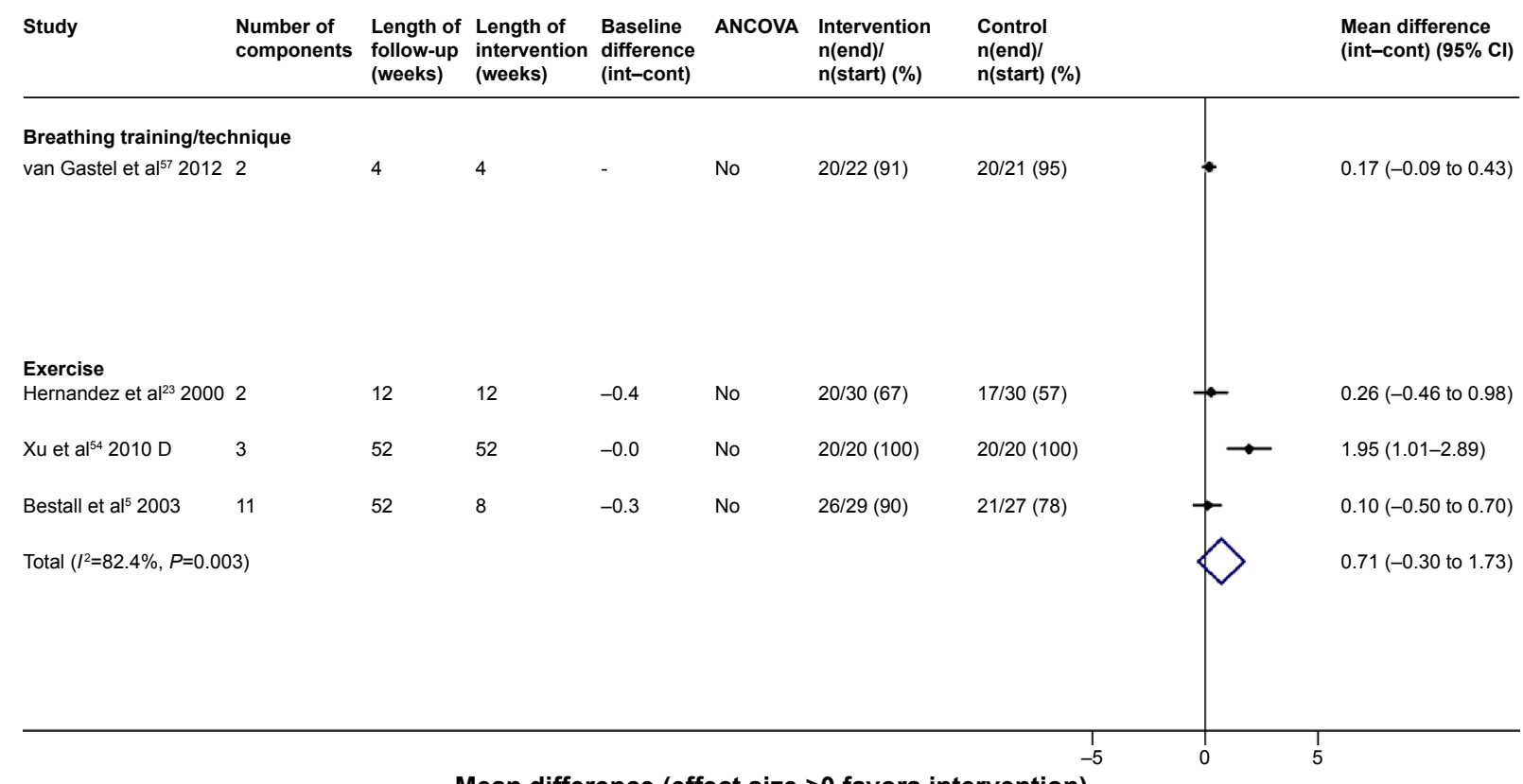

Mean difference (effect size $>0$ favors intervention)

Figure S2 HRQoL (CRQ) at final follow-up for comparisons assessing the effects of one additional component of self-management.

Note: $\mathrm{D}=$ rehabilitation (traditional and modern) + qigong + breathing training + limb training vs modern rehabilitation + breathing training + limb training

Abbreviations: ANCOVA, analysis of covariance; Cl, confidence interval; HRQoL, health-related quality of life; CRQ, Chronic Respiratory disease Questionnaire. 


\begin{tabular}{|c|c|c|c|c|c|c|c|c|c|c|}
\hline Study & $\begin{array}{l}\text { Number of } \\
\text { components }\end{array}$ & $\begin{array}{l}\text { Length of } \\
\text { follow-up } \\
\text { (weeks) }\end{array}$ & $\begin{array}{l}\text { Length of } \\
\text { intervention } \\
\text { (weeks) }\end{array}$ & $\begin{array}{l}\text { Baseline } \\
\text { difference } \\
\text { (int-cont) }\end{array}$ & ANCOVA & $\begin{array}{l}\text { Intervention } \\
\text { n(end)/ } \\
\text { n(start) (\%) }\end{array}$ & $\begin{array}{l}\text { Control } \\
\text { n(end)/ } \\
\text { n(start) (\%) }\end{array}$ & & & $\begin{array}{l}\text { Mean difference } \\
\text { (int-cont) }(95 \% \mathrm{Cl})\end{array}$ \\
\hline \multicolumn{11}{|c|}{ Follow-up 13 weeks or less } \\
\hline Murphy et al ${ }^{41} 2005$ & 1 & 6 & 6 & 4.9 & No & $13 / 13(100)$ & $13 / 13(100)$ & & & $4.10(-11.28$ to 19.48$)$ \\
\hline Hospes et $\mathrm{al}^{25} 2009$ & 2 & 12 & 12 & 2.5 & No & $18 / 20(90)$ & $17 / 19(89)$ & & & $4.10(-6.03$ to 14.23$)$ \\
\hline Katiyar and Bihari ${ }^{30} 2006$ & 2 & 13 & 13 & 1.0 & No & 23/24 (96) & $22 / 24(92)$ & & $\bullet$ & $5.00(4.06-5.94)$ \\
\hline Chan et al ${ }^{11} 2010 \mathrm{~B}$ & 3 & 13 & 13 & -2.4 & No & $69 / 69(100)$ & $34 / 34(100)^{*}$ & & & $3.00(-3.38$ to 9.38$)$ \\
\hline Chan et al ${ }^{11} 2010 \mathrm{~A}$ & 4 & 13 & 13 & 3.3 & No & $70 / 70(100)$ & $34 / 34(100)^{*}$ & & - & $1.60(-4.58$ to 7.78$)$ \\
\hline Total $\left(I^{2}=0.0 \%, P=0.824\right)$ & & & & & & & & & $\ell$ & $4.87(3.96-5.79)$ \\
\hline \multicolumn{11}{|l|}{ Follow-up over 26 weeks } \\
\hline Gohl et al ${ }^{58} 2006$ & 2 & 52 & 52 & 2.5 & No & $10 / 10(100)$ & $9 / 9(100)$ & & 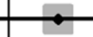 & $8.50(-2.29$ to 19.29$)$ \\
\hline
\end{tabular}

Figure S3 HRQoL (SGRQ) outcomes for exercise-only interventions versus usual care/sham intervention.

Note: *The control group that has been halved in size (split between two comparisons). A = t'ai chi qigong vs control. B = exercise vs control.

Abbreviations: ANCOVA, analysis of covariance; $\mathrm{Cl}$, confidence interval; HRQoL, health-related quality of life; SGRQ, St George's respiratory questionnaire.

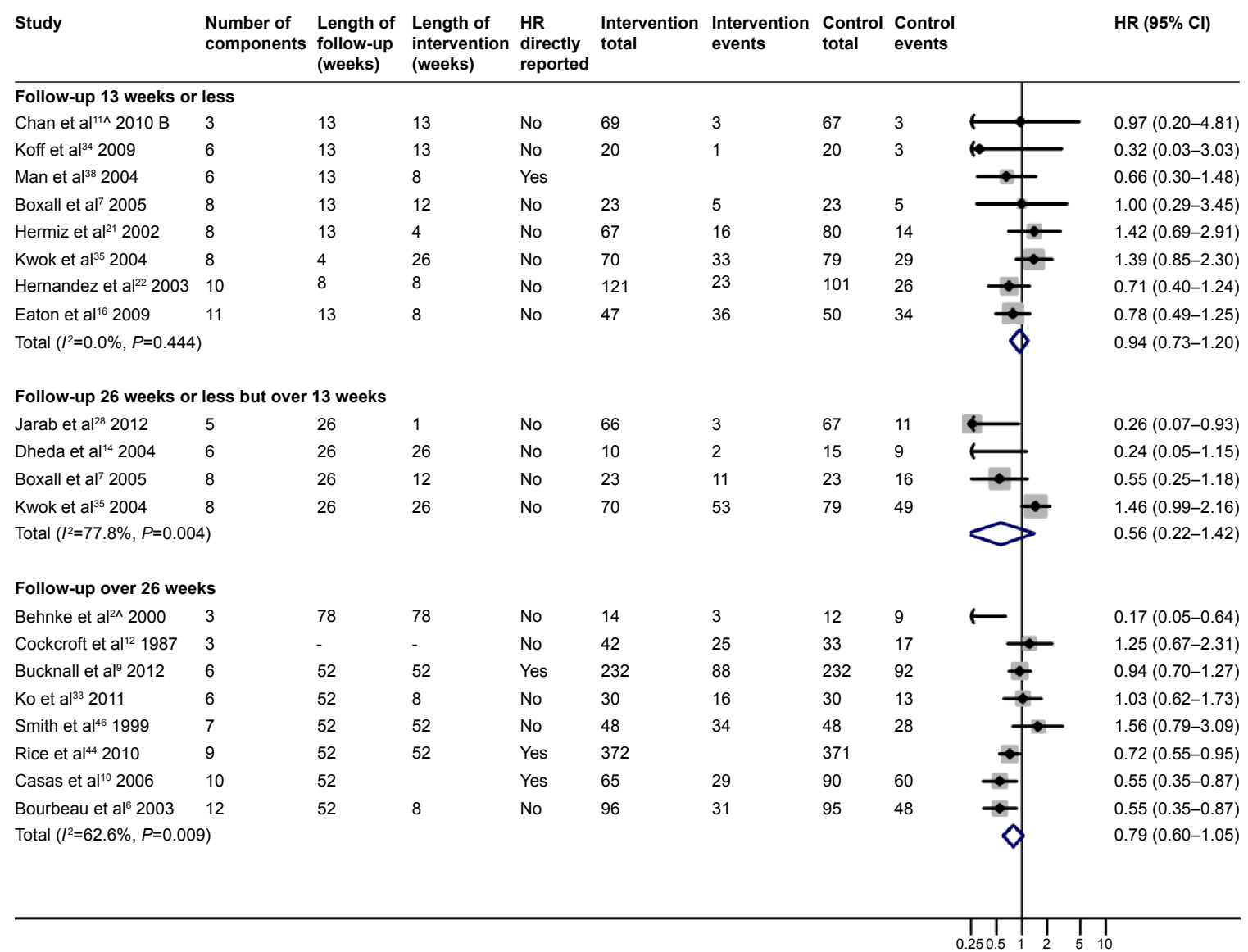

\section{Hazard ratio (effect size $<1$ favors intervention)}

Figure S4 Hospital admissions for multicomponent self-management interventions versus usual care.

Notes: $\mathrm{B}=$ exercise vs control. ^ Several papers are represented by this lead publication.

Abbreviations: ANCOVA, analysis of covariance; $\mathrm{Cl}$, confidence interval; $\mathrm{HR}$, hazard ratio. 


\begin{tabular}{|c|c|c|c|c|c|c|c|c|c|}
\hline Study & $\begin{array}{l}\text { Number of } \\
\text { components }\end{array}$ & $\begin{array}{l}\text { Length of } \\
\text { follow-up } \\
\text { (weeks) }\end{array}$ & $\begin{array}{l}\text { Length of } \\
\text { intervention } \\
\text { (weeks) }\end{array}$ & $\begin{array}{l}\text { Baseline } \\
\text { difference } \\
\text { (int-cont) }\end{array}$ & ANCOVA & $\begin{array}{l}\text { Intervention } \\
\text { n(end)/ } \\
\text { n(start) (\%) }\end{array}$ & $\begin{array}{l}\text { Control } \\
\mathrm{n} \text { (end)/ } \\
\mathrm{n} \text { (start) (\%) }\end{array}$ & & $\begin{array}{l}\text { Mean difference } \\
\text { (int-cont) }(95 \% \mathrm{Cl})\end{array}$ \\
\hline \multicolumn{10}{|l|}{ Follow-up 13 weeks or less } \\
\hline Behnke et $\mathrm{al}^{2} 2000$ & 3 & 13 & 26 & 0.1 & No & $15 / 23(65)$ & $15 / 23(65)$ & $\leftarrow$ & $1.05(0.56-1.54)$ \\
\hline Berry et $\mathrm{al}^{4} 2010$ & 3 & 13 & 48 & & No & $61 / 87(70)$ & $69 / 89(78)$ & & $-0.20(-0.48$ to 0.08$)$ \\
\hline Xu et al ${ }^{54} 2010 \mathrm{~A}$ & 3 & 13 & 52 & -0.1 & No & $20 / 20(100)$ & $20 / 20(100)$ & & $1.17(0.13-2.21)$ \\
\hline Janaudis-Ferreira et $\mathrm{al}^{27} 2011$ & 4 & 6 & 6 & -0.4 & No & $13 / 17(76)$ & $18 / 19(95)$ & & $0.10(-0.36$ to 0.56$)$ \\
\hline Bendstrup et $a^{3} 1997$ & 9 & 12 & 12 & 0.2 & No & $16 / 22(73)$ & $16 / 20(80)$ & & $0.40(-0.11$ to 0.91$)$ \\
\hline Bestall et al ${ }^{5} 2003$ & 11 & 8 & 8 & -0.3 & No & $29 / 29(100)$ & $27 / 27(100)$ & & $0.20(-0.28$ to 0.68$)$ \\
\hline $\mathrm{Oh}^{42} 2003$ & 11 & 8 & 8 & -0.4 & No & $15 / 19(79)$ & $8 / 15(53)$ & & $0.61(-0.18$ to 1.41$)$ \\
\hline Total $\left(I^{2}=75.7 \%, P<0.001\right)$ & & & & & & & & & $0.40(0.01-0.79)$ \\
\hline \multicolumn{10}{|c|}{ Follow-up 26 weeks or less but over 13 weeks } \\
\hline Behnke et $a^{2} 2000$ & 3 & 26 & 26 & 0.1 & No & $15 / 23(65)$ & $15 / 23(65)$ & $\rightarrow$ & $1.95(1.33-2.57)$ \\
\hline Berry et $\mathrm{al}^{4} 2010$ & 3 & 26 & 48 & & No & $61 / 87(70)$ & $69 / 89(78)$ & & $-0.20(-0.48$ to 0.08$)$ \\
\hline Xu et al ${ }^{54} 2010 \mathrm{~A}$ & 3 & 26 & 52 & -0.1 & No & $20 / 20(100)$ & $20 / 20(100)$ & $\rightarrow$ & $2.48(1.42-3.54)$ \\
\hline Bendstrup et al ${ }^{3} 1997$ & 9 & 24 & 12 & 0.2 & No & $16 / 22(73)$ & $16 / 20(80)$ & & $0.85(0.19-1.50)$ \\
\hline Bestall et $\mathrm{al}^{5} 2003$ & 11 & 26 & 8 & -0.3 & No & $28 / 29(97)$ & $24 / 27(89)$ & & $0.30(-0.29$ to 0.89$)$ \\
\hline Total $\left(I^{2}=93.2 \%, P<0.001\right)$ & & & & & & & & & $1.02(0.05-1.98)$ \\
\hline \multicolumn{10}{|l|}{ Follow-up over 26 weeks } \\
\hline Berry et $\mathrm{al}^{4} 2010$ & 3 & 52 & 48 & & No & $61 / 87(70)$ & 69/89 (78) & & $0.00(-0.28$ to 0.28$)$ \\
\hline Xu et $a^{54} 2010 \mathrm{~A}$ & 3 & 52 & 52 & -0.1 & No & $20 / 20(100)$ & $20 / 20(100)$ & $\leftarrow$ & $3.73(2.76-4.70)$ \\
\hline Bestall et al ${ }^{5} 2003$ & 11 & 52 & 8 & -0.3 & No & $26 / 29(90)$ & $21 / 27(78)$ & & $0.10(-0.50$ to 0.70$)$ \\
\hline Total $\left(I^{2}=96.2 \%, P<0.001\right)$ & & & & & & & & & $1.21(-0.47$ to 2.88$)$ \\
\hline
\end{tabular}

Mean difference (effect size $>0$ favors intervention)

Figure S5 HRQoL (CRQ) outcomes for multicomponent self-management intervention versus usual care.

Note: $A$ = rehabilitation (traditional and modern) + qigong + breathing training + limb training vs UC.

Abbreviations: ANCOVA, analysis of covariance; Cl, confidence interval; HRQoL, health-related quality of life; CRQ, Chronic Respiratory disease Questionnaire; UC, usual care.

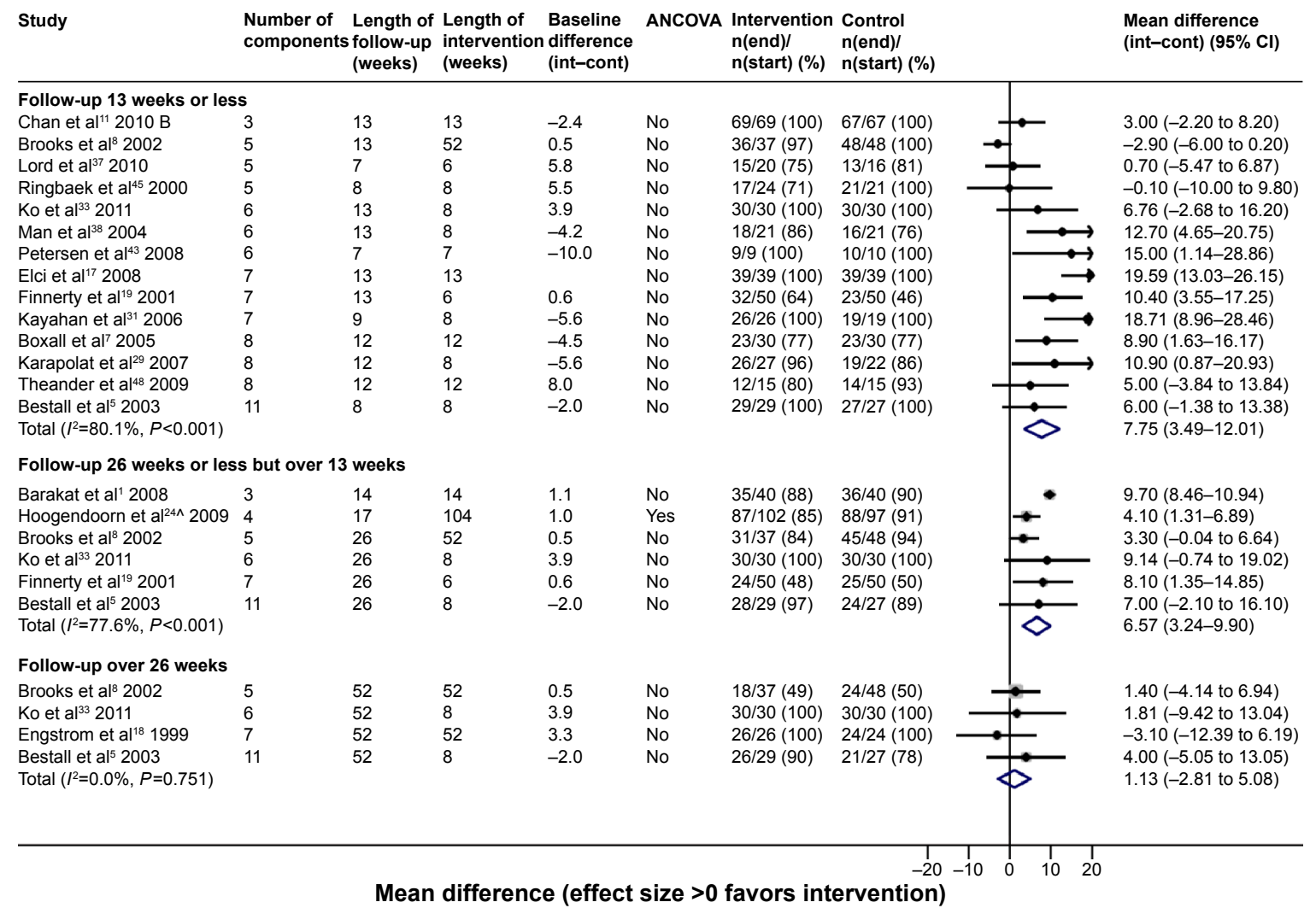

Figure S6 HRQoL (SGRQ) outcomes for multicomponent self-management interventions including supervised exercise versus usual care/control.

Notes: $\mathrm{B}=$ exercise vs control. ^ Several papers are represented by this lead publication.

Abbreviations: ANCOVA, analysis of covariance; CI, confidence interval; HRQoL, health-related quality of life; SGRQ, St George's respiratory questionnaire. 


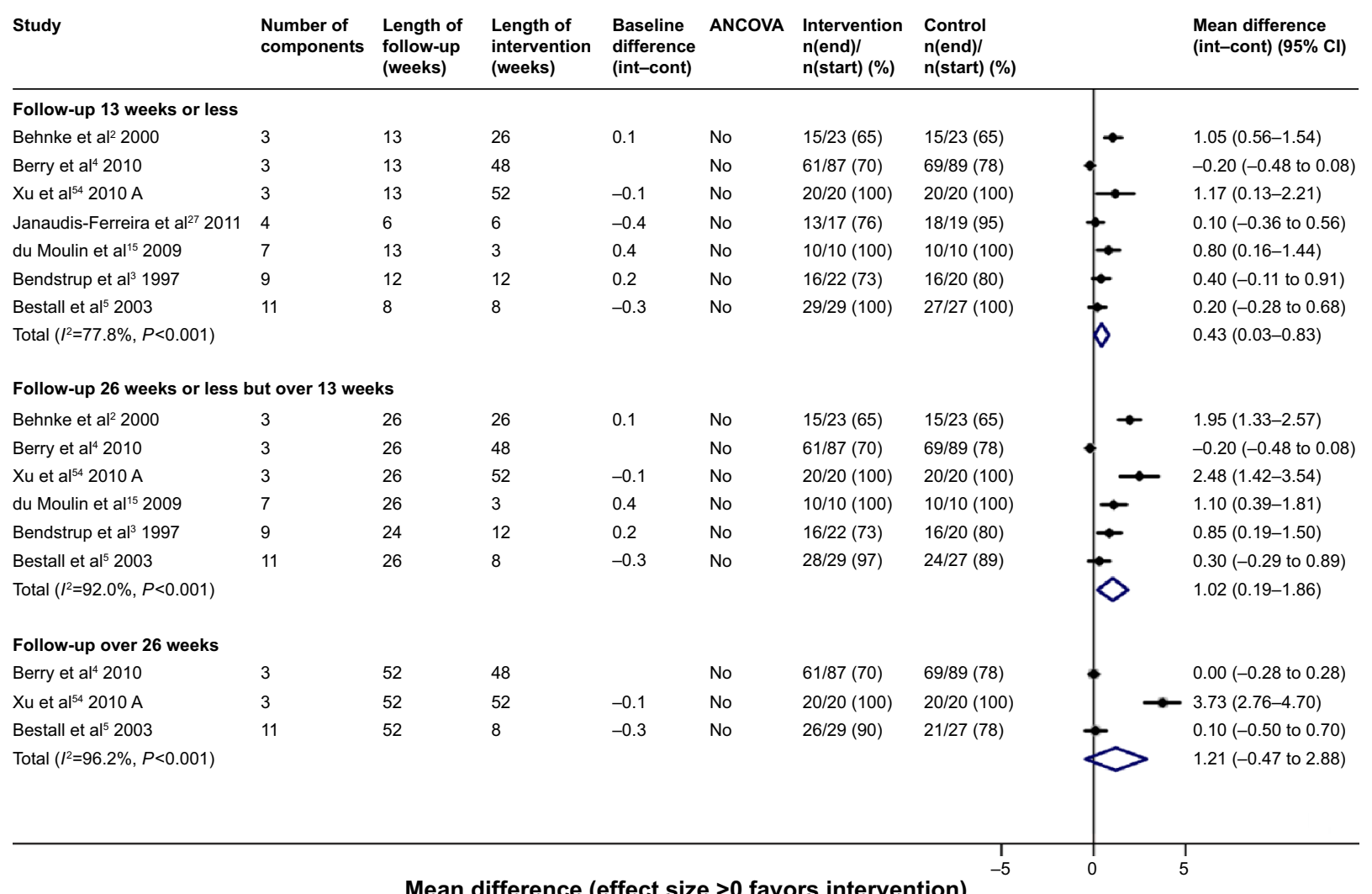

Figure S7 HRQoL (CRQ) outcomes for multicomponent self-management interventions including supervised exercise versus usual care/control. Note: $\mathrm{A}$ = rehabilitation (traditional and modern) + qigong + breathing training + limb training vs UC.

Abbreviations: ANCOVA, analysis of covariance; Cl, confidence interval; HRQoL, health-related quality of life; CRQ, Chronic Respiratory disease Questionnaire; UC, usual care.

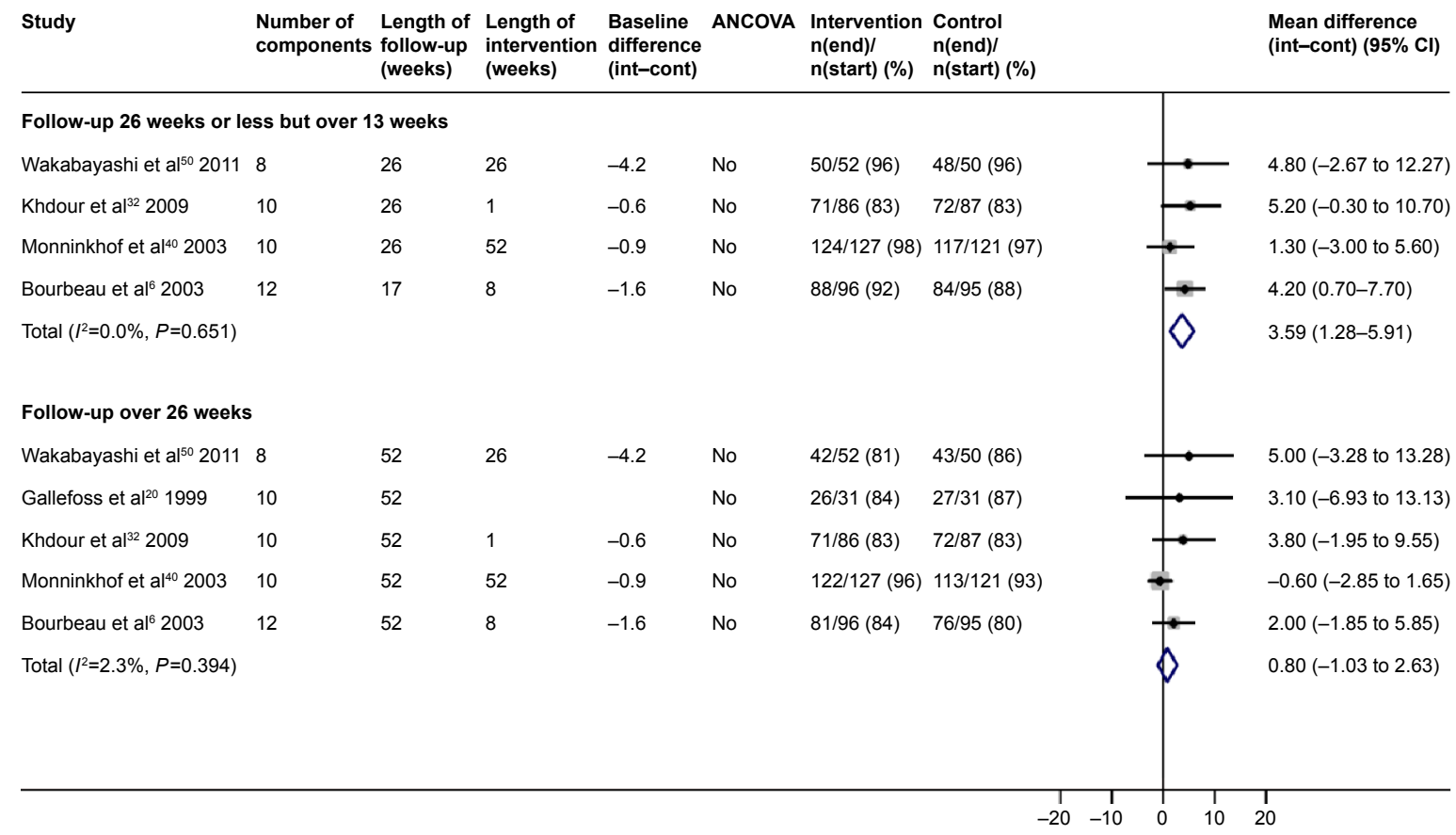

Mean difference (effect size $>0$ favors intervention)

Figure S8 HRQoL (SGRQ) outcomes for multicomponent self-management interventions with structured, unsupervised exercise versus usual care/control. Abbreviations: ANCOVA, analysis of covariance; CI, confidence interval; HRQoL, health-related quality of life; SGRQ, St George's respiratory questionnaire. 


\begin{tabular}{|c|c|c|c|c|c|c|c|c|}
\hline Study & $\begin{array}{l}\text { Number of } \\
\text { components }\end{array}$ & $\begin{array}{l}\text { Length of } \\
\text { follow-up } \\
\text { (weeks) }\end{array}$ & $\begin{array}{l}\text { Length of } \\
\text { intervention } \\
\text { (weeks) }\end{array}$ & $\begin{array}{l}\text { Baseline } \\
\text { difference } \\
\text { (int-cont) }\end{array}$ & ANCOVA & $\begin{array}{l}\text { Intervention } \\
\text { n(end)/ } \\
\text { n(start) (\%) }\end{array}$ & $\begin{array}{l}\text { Control } \\
\text { n(end)/ } \\
\text { n(start) (\%) }\end{array}$ & $\begin{array}{l}\text { Mean difference } \\
\text { (int-cont) }(95 \% \mathrm{Cl})\end{array}$ \\
\hline \multicolumn{9}{|c|}{ Follow-up 13 weeks or less } \\
\hline Hermiz et al ${ }^{21} 2002$ & 8 & 13 & 4 & 3.0 & No & $67 / 84(80)$ & $80 / 93(86)$ & $1.32(-2.97$ to 5.61$)$ \\
\hline \multicolumn{9}{|c|}{ Follow-up 26 weeks or less but over 13 weeks } \\
\hline Jarab et $\mathrm{al}^{28} 2012$ & 5 & 26 & 1 & 0.4 & No & $63 / 66(95)$ & $64 / 67(96)$ & $0.80(-3.84$ to 5.44$)$ \\
\hline Dheda et al ${ }^{14} 2004$ & 6 & 26 & 26 & & No & $10 / 15(67)$ & $15 / 18(83)$ & $15.00(2.45-27.55)$ \\
\hline Wood-Baker et al ${ }^{53} 2006$ & 12 & 26 & 1 & -0.8 & No & $61 / 67(91)$ & $62 / 72(86)$ & $-2.30(-6.19$ to 1.59$)$ \\
\hline Total $\left(I^{2}=71.2 \%, P=0.031\right)$ & & & & & & & & $1.87(-4.43$ to 8.18$)$ \\
\hline \multicolumn{9}{|l|}{ Follow-up over 26 weeks } \\
\hline Soler et $\mathrm{al}^{47} 2006$ & 7 & 52 & 52 & -10.6 & No & $13 / 13(100)$ & $13 / 13(100)$ & $14.60(3.90-25.30)$ \\
\hline Rice et al ${ }^{44} 2010$ & 9 & 52 & 52 & & No & $223 / 372(60)$ & $204 / 371(55)$ & $5.10(2.55-7.65)$ \\
\hline Casas et al ${ }^{10 \wedge} 2006$ & 10 & 52 & & -9.3 & No & $21 / 44(48)$ & $41 / 69(59)$ & $2.39(-5.78$ to 10.56$)$ \\
\hline Wood-Baker et al ${ }^{53} 2006$ & 12 & 52 & 1 & -0.8 & No & $54 / 67(81)$ & $58 / 72(81)$ & $-1.70(-5.83$ to 2.43$)$ \\
\hline Total $\left(I^{2}=74.6 \%, P=0.008\right)$ & & & & & & & & $3.88(-1.39$ to 9.14$)$ \\
\hline
\end{tabular}

Mean difference (effect size $>0$ favors intervention)

Figure S9 HRQoL (SGRQ) outcomes for multicomponent self-management interventions with exercise counseling only versus usual care/control. Note: ^ ${ }^{\wedge}$ Several papers are represented by this lead publication.

Abbreviations: ANCOVA, analysis of covariance; Cl, confidence interval; HRQoL, health-related quality of life; SGRQ, St George's respiratory questionnaire.

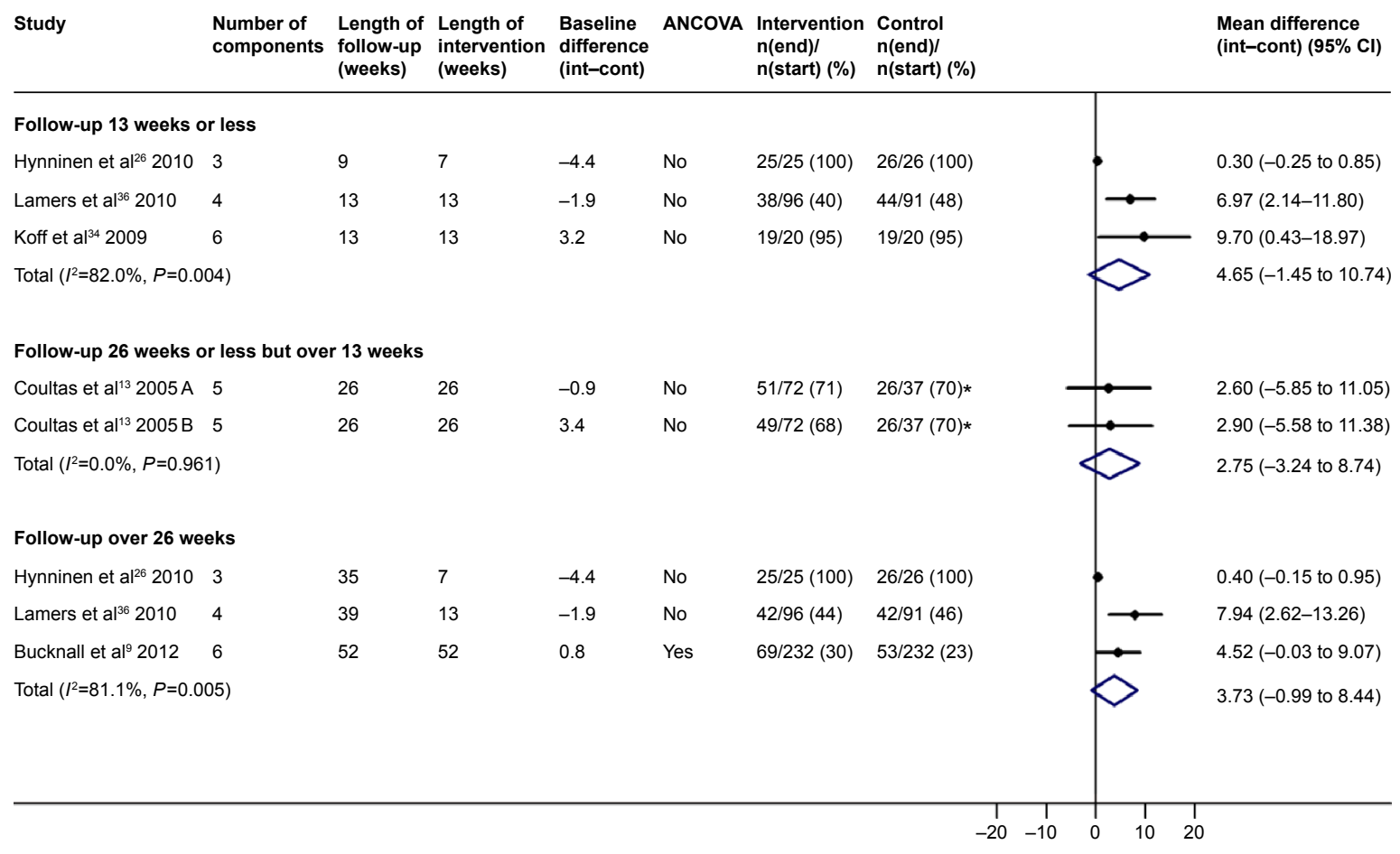

Mean difference (effect size $>0$ favors intervention)

Figure SIO HRQoL (SGRQ) outcomes for multicomponent self-management interventions without an exercise element versus usual care/control.

Notes: $*$ The control group that has been halved in size (split between two comparisons). A = nurse-assisted collaborative management vs UC; $B=$ nurse-assisted medical management vs UC.

Abbreviations: ANCOVA, analysis of covariance; Cl, confidence interval; HRQoL, health-related quality of life; SGRQ, St George's respiratory questionnaire; UC, usual care. 


\section{References}

1. Barakat S, Michele G, George P, Nicole V, Guy A. Outpatient pulmonary rehabilitation in patients with chronic obstructive pulmonary disease. Int J Chron Obstruct Pulmon Dis. 2008;3(1):155-162.

2. Behnke M, Taube C, Kirsten D, Lehnigk B, Jorres RA, Magnussen H. Home-based exercise is capable of preserving hospital-based improvements in severe chronic obstructive pulmonary disease. Respir Med. 2000;94(12):1184-1191.

3. Bendstrup KE, Ingemann JJ, Holm S, Bengtsson B. Out-patient rehabilitation improves activities of daily living, quality of life and exercise tolerance in chronic obstructive pulmonary disease. Eur Respir J. 1997;10(12):2801-2806.

4. Berry MJ, Rejeski WJ, Miller ME, et al. A lifestyle activity intervention in patients with chronic obstructive pulmonary disease. Respir Med. 2010;104(6):829-839.

5. Bestall JC, Paul EA, Garrod R, et al. Longitudinal trends in exercise capacity and health status after pulmonary rehabilitation in patients with COPD. Respir Med. 2003;97(2):173-180.

6. Bourbeau J, Julien M, Maltais F, et al. Reduction of hospital utilization in patients with chronic obstructive pulmonary disease: a disease-specific self-management intervention. Arch Intern Med. 2003;163(5):585-591.

7. Boxall AM, Barclay L, Sayers A, Caplan GA. Managing chronic obstructive pulmonary disease in the community. A randomized controlled trial of home-based pulmonary rehabilitation for elderly housebound patients. J Cardiopulm Rehabil. 2005;25(6):378-385.

8. Brooks D, Krip B, Mangovski-Alzamora S, Goldstein RS. The effect of postrehabilitation programmes among individuals with chronic obstructive pulmonary disease. Eur Respir J. 2002;20(1):20-29.

9. Bucknall CE, Miller G, Lloyd SM, et al. Glasgow supported selfmanagement trial (GSuST) for patients with moderate to severe COPD: randomised controlled trial. BMJ. 2012;344:e1060.

10. Casas A, Troosters T, Garcia-Aymerich J, et al. Integrated care prevents hospitalisations for exacerbations in COPD patients. Eur Respir J. 2006;28(1):123-130.

11. Chan AW, Lee A, Suen LK, Tam WW. Effectiveness of a Tai chi Qigong program in promoting health-related quality of life and perceived social support in chronic obstructive pulmonary disease clients. Qual Life Res. 2010;19(5):653-664.

12. Cockcroft A, Bagnall P, Heslop A, et al. Controlled trial of respiratory health worker visiting patients with chronic respiratory disability. $\mathrm{Br}$ Med J (Clin Res Ed). 1987;294(6566):225-228.

13. Coultas D, Frederick J, Barnett B, Singh G, Wludyka P. A randomized trial of two types of nurse-assisted home care for patients with COPD. Chest. 2005;128(4):2017-2024.

14. Dheda K, Crawford A, Hagan G, Roberts CM. Implementation of British Thoracic Society guidelines for acute exacerbation of chronic obstructive pulmonary disease: Impact on quality of life. Postgrad Med J. 2004;80(941):169-171.

15. du Moulin M, Taube K, Wegscheider K, Behnke M, van den BH. Home-based exercise training as maintenance after outpatient pulmonary rehabilitation. Respiration. 2009;77(2):139-145.

16. Eaton T, Young P, Fergusson W, et al. Does early pulmonary rehabilitation reduce acute health-care utilization in COPD patients admitted with an exacerbation? A randomized controlled study. Respirology. 2009;14(2):230-238.

17. Elci A, Borekci S, Ovayolu N, Elbek O. The efficacy and applicability of a pulmonary rehabilitation programme for patients with COPD in a secondary-care community hospital. Respirology. 2008;13(5):703-707.

18. Engstrom CP, Persson LO, Larsson S, Sullivan M. Long-term effects of a pulmonary rehabilitation programme in outpatients with chronic obstructive pulmonary disease: a randomized controlled study. Scand J Rehabil Med. 1999;31(4):207-213.

19. Finnerty JP, Keeping I, Bullough I, Jones J. The effectiveness of outpatient pulmonary rehabilitation in chronic lung disease: a randomized controlled trial. Chest. 2001;119(6):1705-1710.
20. Gallefoss F, Bakke PS, Rsgaard PK. Quality of life assessment after patient education in a randomized controlled study on asthma and chronic obstructive pulmonary disease. Am J Respir Crit Care Med. 1999; 159(3):812-817.

21. Hermiz O, Comino E, Marks G, et al. Randomised controlled trial of home based care of patients with chronic obstructive pulmonary disease. BMJ. 2002;325(7370):938.

22. Hernandez C, Casas A, Escarrabill J, et al. Home hospitalisation of exacerbated chronic obstructive pulmonary disease patients. Eur Respir J. 2003;21(1):58-67.

23. Hernandez MT, Rubio TM, Ruiz FO, et al. Results of a home-based training program for patients with COPD. Chest. 2000;118(1): 106-114.

24. Hoogendoorn M, van Wetering CR, Schols AM, Rutten-van Molken MP. Self-report versus care provider registration of healthcare utilization: impact on cost and cost-utility. Int J Technol Assess Health Care. 2009;25(4):588-595.

25. Hospes G, Bossenbroek L, Ten Hacken NH, van HP, de Greef MH. Enhancement of daily physical activity increases physical fitness of outclinic COPD patients: results of an exercise counseling program. Patient Educ Couns. 2009;75(2):274-278.

26. Hynninen MJ, Bjerke N, Pallesen S, Bakke PS, Nordhus IH. A randomized controlled trial of cognitive behavioral therapy for anxiety and depression in COPD. Respir Med. 2010;104(7):986-994.

27. Janaudis-Ferreira T, Hill K, Goldstein RS, et al. Resistance arm training in patients with COPD: A Randomized Controlled Trial. Chest. 2011;139(1):151-158.

28. Jarab AS, Alqudah SG, Khdour M, Shamssain M, Mukattash TL. Impact of pharmaceutical care on health outcomes in patients with COPD. Int J Clin Pharm. 2012;34(1):53-62.

29. Karapolat H, Atasever A, Atamaz F, et al. Do the benefits gained using a short-term pulmonary rehabilitation program remain in COPD patients after participation? Lung. 2007;185(4):221-225.

30. Katiyar SK, Bihari S. Role of pranayama in rehabilitation of copd patients - a randomized controlled study. Indian Journal of Allergy Asthma Immunology. 2006;20(2):98-104.

31. Kayahan B, Karapolat H, Atyntoprak E, Atasever A, Ozturk O. Psychological outcomes of an outpatient pulmonary rehabilitation program in patients with chronic obstructive pulmonary disease. Respir Med. 2006;100(6):1050-1057.

32. Khdour MR, Kidney JC, Smyth BM, McElnay JC. Clinical pharmacyled disease and medicine management programme for patients with COPD. Br J Clin Pharmacol. 2009;68(4):588-598.

33. Ko FW, Dai DL, Ngai J, et al. Effect of early pulmonary rehabilitation on health care utilization and health status in patients hospitalized with acute exacerbations of COPD. Respirology. 2011;16(4):617-624.

34. Koff PB, Jones RH, Cashman JM, Voelkel NF, Vandivier RW. Proactive integrated care improves quality of life in patients with COPD. Eur Respir J. 2009;33(5):1031-1038.

35. Kwok T, Lum CM, Chan HS, Ma HM, Lee D, Woo J. A randomized, controlled trial of an intensive community nurse-supported discharge program in preventing hospital readmissions of older patients with chronic lung disease. J Am Geriatr Soc. 2004;52(8):1240-1246.

36. Lamers F, Jonkers CC, Bosma H, et al. Improving quality of life in depressed COPD patients: effectiveness of a minimal psychological intervention. COPD. 2010;7(5):315-322.

37. Lord VM, Cave P, Hume VJ, et al. Singing teaching as a therapy for chronic respiratory disease - a randomised controlled trial and qualitative evaluation. BMC Pulmonary Medicine. 2010;10:41.

38. Man WD, Polkey MI, Donaldson N, Gray BJ, Moxham J. Community pulmonary rehabilitation after hospitalisation for acute exacerbations of chronic obstructive pulmonary disease: randomised controlled study. BMJ. 2004;329(7476):1209.

39. McGeoch GR, Willsman KJ, Dowson CA, et al. Self-management plans in the primary care of patients with chronic obstructive pulmonary disease. Respirology. 2006;11(5):611-618. 
40. Monninkhof E, van der Valk P, van der Palen J, van Herwaarden C, Zielhuis G. Effects of a comprehensive self-management programme in patients with chronic obstructive pulmonary disease. Eur Respir J. 2003;22(5):815-820.

41. Murphy N, Bell C, Costello RW. Extending a home from hospital care programme for COPD exacerbations to include pulmonary rehabilitation. Respir Med. 2005;99(10):1297-1302.

42. Oh EG. The effects of home-based pulmonary rehabilitation in patients with chronic lung disease. Int J Nurs Stud. 2003;40(8):873-879.

43. Petersen AM, Mittendorfer B, Magkos F, Iversen M, Pedersen BK. Physical activity counteracts increased whole-body protein breakdown in chronic obstructive pulmonary disease patients. Scand J Med Sci Sports. 2008;18(5):557-564.

44. Rice KL, Dewan N, Bloomfield HE, et al. Disease management program for chronic obstructive pulmonary disease: a randomized controlled trial. Am J Respir Crit Care Med. 2010;182(7):890-896.

45. Ringbaek TJ, Broendum E, Hemmingsen L, et al. Rehabilitation of patients with chronic obstructive pulmonary disease. Exercise twice a week is not sufficient! Respir Med. 2000;94(2):150-154.

46. Smith BJ, Appleton SL, Bennett PW, et al. The effect of a respiratory home nurse intervention in patients with chronic obstructive pulmonary disease (COPD). Aust N Z J Med. 1999;29(5):718-725.

47. Soler JJ, Martinez-Garcia MA, Roman P, et al. [Effectiveness of a specific program for patients with chronic obstructive pulmonary disease and frequent exacerbations]. [Spanish]. Archivos de Bronconeumologia. 2006;42(10):501-508.

48. Theander K, Jakobsson P, Jorgensen N, Unosson M. Effects of pulmonary rehabilitation on fatigue, functional status and health perceptions in patients with chronic obstructive pulmonary disease: a randomized controlled trial. Clinical Rehabilitation. 2009;23(2):125-136.

49. Trappenburg JC, Monninkhof EM, Bourbeau J, et al. Effect of an action plan with ongoing support by a case manager on exacerbation-related outcome in patients with COPD: a multicentre randomised controlled trial. Thorax. 2011;66(11):977-984.
50. Wakabayashi R, Motegi T, Yamada K, et al. Efficient integrated education for older patients with chronic obstructive pulmonary disease using the Lung Information Needs Questionnaire. Geriatr Gerontol Int. 2011;11(4):422-430.

51. Watson PB, Town GI, Holbrook N, et al. Evaluation of a self-management plan for chronic obstructive pulmonary disease. Eur Respir J. 1997;10(6):1267-1271.

52. Weekes CE, Emery PW, Elia M. Dietary counselling and food fortification in stable COPD: a randomised trial. Thorax. 2009;64(4): 326-331.

53. Wood-Baker R, McGlone S, Venn A, Walters EH. Written action plans in chronic obstructive pulmonary disease increase appropriate treatment for acute exacerbations. Respirology. 2006;11(5):619-626.

54. Xu Y-H, Wang J-H, Li H-F, et al. Efficacy of integrative respiratory rehabilitation training in exercise ability and quality of life of patients with chronic obstructive pulmonary disease in stable phase: A randomized controlled trial. [Chinese]. Journal of Chinese Integrative Medicine. 2010;8(5):432-437.

55. Yamaguti WP, Claudino RC, Neto AP, et al. Diaphragmatic breathing training program improves abdominal motion during natural breathing in patients with chronic obstructive pulmonary disease: a randomized controlled trial. Archives of Physical Medicine \& Rehabilitation. 2012;93(4):571-577.

56. Bauldoff GS, Hoffman LA, Zullo TG, Sciurba FC. Exercise maintenance following pulmonary rehabilitation: effect of distractive stimuli. Chest. 2002;122(3):948-954.

57. Van Gestel AJ, Kohler M, Steier J, Teschler S, Russi EW, Teschler H. The effects of controlled breathing during pulmonary rehabilitation in patients with COPD. Respiration. 2012;83(20):115-124.

58. Gohl O, Linz H, Schonleben T, Otte B, Weineck J, Worth H. [Benefits of a multimodular outpatient training program for patients with COPD.] Pneumologie. 2006;60(9):529-536. [Erratum published in Pneumologie. 2006;60(12):783] German.
International Journal of COPD

\section{Publish your work in this journal}

The International Journal of COPD is an international, peer-reviewed journal of therapeutics and pharmacology focusing on concise rapid reporting of clinical studies and reviews in COPD. Special focus is given to the pathophysiological processes underlying the disease, intervention programs, patient focused education, and self management protocols.

\section{Dovepress}

This journal is indexed on PubMed Central, MedLine and CAS. The manuscript management system is completely online and includes a very quick and fair peer-review system, which is all easy to use. Visit http://www.dovepress.com/testimonials.php to read real quotes from published authors. 